Document downloaded from:

http://hdl.handle.net/10251/72294

This paper must be cited as:

Merello Giménez, P.; Beltrán Medina, P.; García Diego, FJ. (2016). Quantitative noninvasive method for damage evaluation in frescoes: Ariadne's House (Pompeii, Italy). Environmental Earth Sciences. 75(2). doi:10.1007/s12665-015-5066-3.

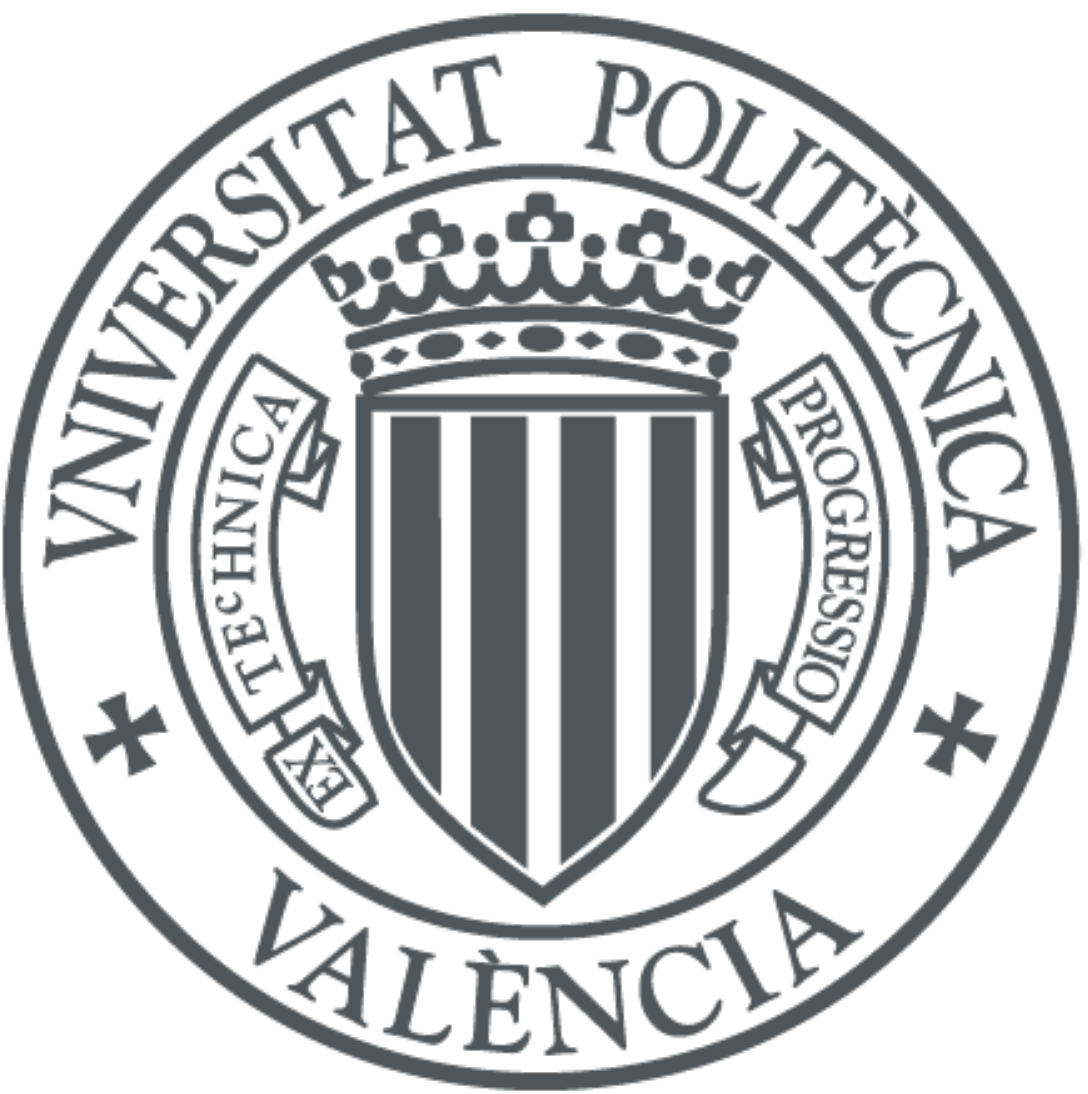

The final publication is available at

https://dx.doi.org/10.1007/s12665-015-5066-3

Copyright Springer Verlag (Germany)

Additional Information 


\section{Quantitative non-invasive method for salts efflorescences damage 2 evaluation in frescoes: Ariadne's House (Pompeii, Italy)}

3 P. Merello ${ }^{1,2}$, P. Beltrán ${ }^{2}$, F-J. García-Diego ${ }^{2,3, *}$.

$4{ }^{1}$ Instituto Valenciano de Conservación y Restauración de Bienes Culturales (IVC+R). 5 Complejo Socio-Educativo de Penyeta Roja s/n. 12080 Castellón, Spain. Email: 6 palomamerello@outlook.com

$7 \quad{ }^{2}$ Department of Applied Physics. Universitat Politècnica de València. Av. de los Naranjos s/n. 46022 Valencia, Spain. Email: pbeltran@ fis.upv.es (P. B.).

${ }^{3}$ Centro de Tecnologías Físicas. Universitat Politècnica de València, Av. de los Naranjos s/n. 1046022 Valencia, Spain.

11 All authors contributed equally to this work.

12 * Author to whom correspondence should be addressed; fjgarcid@ upv.es (F-J. G-D).

Abstract: The preventive conservation is based on acting on the causes of deterioration of cultural heritage to minimize damage, extending its lifetime and minimizing the costs of restoration. In these terms, damage caused by salts is one of the main focuses of study in immovable heritage. In this paper a quantitative method of recording and assessment of damage in frescoes caused by salt efflorescences is presented. Damage mapping has been performed with a colour scale of six values for two fresco paintings of two walls at Ariadne's House (Pompeii, Italy), subsequently this information has been transferred to a data matrix which and statistical analysis of Variance (ANOVA) has been applied . ANOVA results show significant differences for the vertical and the horizontal axis depending on the different stages of damage. These differences also depend on the wall, which may be due to intrinsic differences such as materials of different restorations, the orientation of the wall, etc. or extrinsic differences and variations in temperature and relative humidity, etc. This methodology may be used in the future to quantify the influence of different variables on the extent of the salts damage as well as determine and monitor how evolve salts in a determined facing.

Keywords: damage mapping; preventive conservation; salt efflorescences; ANOVA.

\section{Acknowledgments}

This work was partially supported by the Spanish Government (Ministerio de Economía y Competitividad) under projects HAR2013-47895-C2-1-P and HAR2013-47895-C2-2-P. This publication is part of the program of valorisation and combined resources of the I+D+i of VLC/CAMPUS and has been partially supported by the Ministry of Education, Culture and Sports as part of the program of international excellence campus (PAID 06-14). 


\section{INTRODUCTION}

2 Ariadne's House is one of the biggest stately domus of the private Pompeian architecture (1700 m2) and

3 is located in the "Regio" VII, insula 4 (Pompeii, Italy), located at the centre of the city, less than 100 4 meters from the forum (Pesando 2007). Ariadne's House was first excavated between 1832 and 1835 5 (Pesando 1997) and is still being excavated till nowadays. Four of its rooms still conserve frescoes, in 6 order to preserve them; these rooms were roofed in the 70's with transparent polycarbonate covers (Pérez 7 et al. 2013). Afterwards, it was determined by the analysis of data recorded in a microclimatic monitoring 8 campaign that these transparent roofs were causing a greenhouse effect and damaging the frescoes 9 (Merello et al. 2012)]. In 2009-2010 the covers were changed by opaque fibre-cement covers and, after a 10 second monitoring campaign, it was determined that the thermo-hygrometric conservation conditions of 11 the frescoes had been improved (Merello et al. 2013).

12 Preventive conservation is a work methodology that is based on controlling the possible deterioration causes of cultural heritage to prevent its occurrence. Currently, the importance of preventive conservation is well recognized, both in terms to prevent the deterioration of cultural heritage as, in economic terms, to reduce the cost of future corrective actions.

In the case of wall paintings, the deterioration process is determined by factors such as petrographical and chemical characteristics of the materials, presence of mineral salts and organic substances on the surfaces, air pollution, sunlight, temperature, water content of the surface, etc. (Arnold and Zehnder 1996; Nevin et al. 2008).

The determination of water and salt distribution in brickwork and stonework is a frequent problem in cultural heritage protection (Weritz et al. 2009), as salt weathering is a major decay mechanism affecting historic architecture and statuary as well as modern buildings and others (Goudie and Viles 1997; Winkler 1994; Rodriguez-Navarro and Doehne 1999; Ruiz-agudo et al. 2011). Special attention to the disintegration of wall paintings caused by salt efflorescences has been considered in other studies (Wüst and Schlüchter 2000).

Frescoes do not have an identical conservation state in its entirety expanse due to the different influence of atmospheric agents (temperature, relative humidity light, etc.), and original materials or those used in past restorations. Therefore, it is necessary to characterize their conservation status quantitative and in detail with a damage mapping. This map is of valuable interest to help the restorer in his work, to develop restoration budgets or to perform crossed analyses with other control data (such as thermo-hygrometric data).

There are two main methods of damage mapping commonly used in cultural heritage and, usually, based on visual inspection; the monument mapping method (Hamamcioglu-Turan and Akbaylar 2011) and a staging system approach (UAS method - Unit, Area, Spread) (Warke et al. 2003).

In mapping method, different weathering forms (e.g. cracks, loss of material, colour changes, plants colonization) are evaluated in a plane and a score based on their severity and extent is given to each one. Later, each weathering form is scored in each area, all scores are combined and a final score of the area (from 0-5) is given. Finally, a deterioration index is calculated for the entire monument as an average of the score in the different areas (Hamamcioglu-Turan and Akbaylar 2011).

Staging system approach stems from an analogy between cancer patients treatment and the conservation of stone structures (Warke et al. 2003). Stages of deterioration (usually 4 or 5) are defined in detail and assigned to each area (typically a façade) by various experts through visual inspection. The final score for each zone is obtained as the average of the scores assigned by the experts.

Both methods are similar, but mapping method is more global as it evaluates different weathering forms and calculates an overall deterioration score of the site. 
The quantitative results of the damage assessment are scarcely crossed later with other variables. In (Myra et al. 2014), the authors use staging system approach to quantify the level of deterioration. To determine how geochemical and physical descriptors correlate with stage, bivariate correlation analysis was performed on all data; only cations, often associated with soil salinity, significantly correlated with stage.

However, the weakness of both methods for statistical analysis is that the study area (a façade, a fresco, etc.) is considered as a whole (having a single quantitative value of damage) when performing crossed analysis with other variables, losing valuable information of the diversity within the same study area.

In the case of Ariadne's House, after the roof change, is necessary to quantify the current conservation state of the frescoes in order to analyse in the future how this change has affected them.

The aim of this paper is to propose a methodology for mapping salt damage in frescoes, in order to compare different walls, quantify damage and cross this data with data from temperature, relative humidity, light or salt analytics in future studies. The current conservation state of the Ariadne's House frescoes through a numerical damage scale is quantitatively documented, performing a visual colour mapping and translating it into a data matrix that encompasses the assessment of each cell of the grid in which the study area (wall) is divided. Subsequently, damage data and its relation to the morphological characteristics of the walls are statistically analysed.

\section{MATERIALS AND METHODS}

\subsection{Definition of salt damage stages}

From the knowledge and advice of different curators and conservators, as well as the common sense, a current state of preservation of the fresco has been developed (Table 1).

Areas with previous restorations or presence of consolidating materials such as mortars etc. have been categorized with a particular stage as "white zones".

A colour scale, intended to reflect the outcome of the evaluation in a simple and visual colorimetric map has been used.

Table 1. Damage stage definition.

\begin{tabular}{|l|l|l|}
\hline Colour & $\begin{array}{l}\text { Numerical scale } \\
\text { equivalence }\end{array}$ & Damage definition \\
\hline Green & 1 & Paint layer. Best conservation state of the studied frescoes. \\
\hline Yellow & 2 & $\begin{array}{l}\text { Paint layer decay or salts efflorescences (superficial cleaning by } \\
\text { mechanical techniques needed) }\end{array}$ \\
\hline Orange & 3 & Intonachino/Intonaco layer \\
\hline Red & 4 & Intonaco/Arriccio layer \\
\hline Burgundy & 5 & Brick wall \\
\hline White & 0 & $\begin{array}{l}\text { Area with previous restoration. The restoration is visually } \\
\text { noticeable. }\end{array}$ \\
\hline
\end{tabular}

\subsection{Frescoes assessment procedure}

The procedure for visual inspection of the damage caused by salt efflorescence on the frescoes of Ariadne's House, is done through a detailed inspection of photographs of an equidistant partition of each wall with a virtual mesh.

33 To take the pictures a Panasonic camera, model TZ10, with a resolution of 12.1 mega pixels has been 
1 To make the grid of the wall and the photographs of each element of the grid, two vertical metal supports of $180 \mathrm{~cm}$, with a subdivision of its height in 6 sections and equidistant spacing between supports of 40 $\mathrm{cm}$ were used. As a result, each element of the mesh, and thus each picture, is a wall section of $30 \times 40 \mathrm{~cm}$. To assess damage in detail, each picture is divided using a grid of 192 elements $2.5 \mathrm{~cm}$ x $2.5 \mathrm{~cm}(12$ elements in the vertical x 16 elements in the horizontal).

The evaluation of the pictures was orderly conducted, per columns and per rooms at the monitor of a computer, allowing zooming on the different elements of the mesh for an accurate assessment of the damage stage.

In this paper, two walls with frescoes of a roofed room (Figure 1) of Ariadne's House are evaluated. Wall 4 (Figure 2.b), facing to the north and restored in 2012, with measures of $450 \mathrm{~cm}$ (high) x $360 \mathrm{~cm}$ (width). Monitored dimensions are $180 \mathrm{~cm}$ (height) x $360 \mathrm{~cm}$ (width). A total of 54 photos (6x9) were taken.

Wall 3 (Figure 2.a), facing to the west, has measures of $450 \mathrm{~cm} \mathrm{x} 480 \mathrm{~cm}$. Monitored dimensions are 180 $\mathrm{cm}$ (height) x $480 \mathrm{~cm}$ (width). A total of 72 (6x12) photos were taken.

The monitored height was $180 \mathrm{~cm}$ since above this height frescoes did not exist or were in a
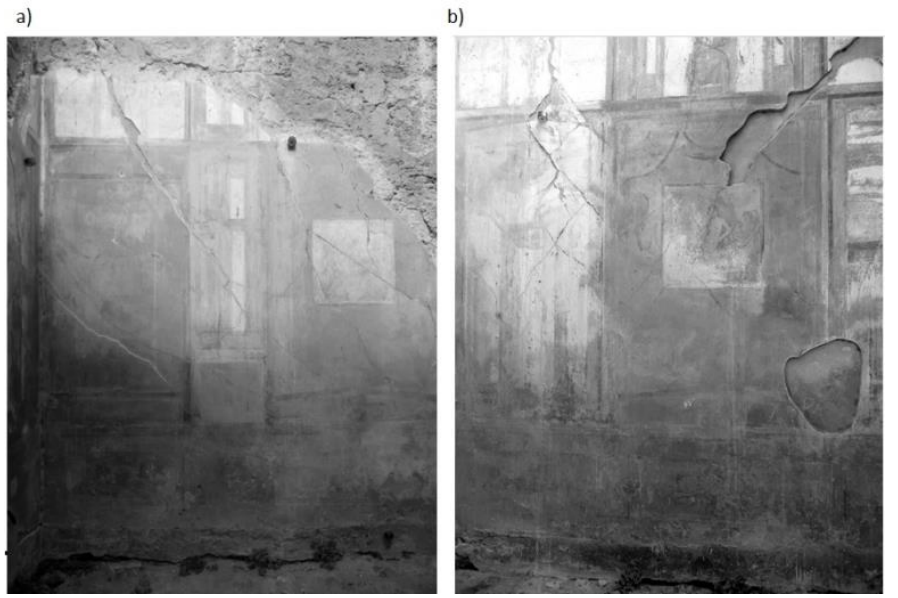

Fig. 1 Map of Ariadne's house and monitored room (room 2)

Fig. 2 A) Frescoes in wall 3 (facing to the west) of room 2. B) Frescoes in wall 4 (facing to the north) of room 2

The sampling and monitoring units are defined as $X(c)_{i j}$, corresponding to the number of colour "c" elements of $2.5 \mathrm{~cm} \times 2.5 \mathrm{~cm}$ present in row (height) $i$ (i=\{1,.,72\} for both walls) of column (width) $j$ 
column has a width of $40 \mathrm{~cm}$, since it is considered a priori that significant differences may be more in the

2 vertical axis (rows) in the horizontal (column).

3 After transferring colorimetric information to a damage data matrix, there is a data matrix of $864 \times 9$ for 4 wall 3; 864 observations (12 sample columns x 72 inspected items/column) and 9 variables (6 damage 5 stages, row $i$, column $j$, row height $i$ ). For wall 4 there is a $648 \times 9$ data matrix; 648 observations ( 9 sample columns $\mathrm{x} 72$ inspected items/column) and the same 9 variables.

7

\subsection{Analysis of Variance (ANOVA)}

To study the effect of the presence of the different salts damage levels (categorized as colours), different ANOVA models were tested for data recorded in 2014, considering the following factors: one factor for each damage level (dummy variables green, yellow, orange, red, burgundy and white, which take value 1 if $\mathrm{X}(\mathrm{c})_{\mathrm{ij}}>0$, and 0 otherwise) and wall (taking value 3,4). ANOVAs were performed using the software Statgraphics 5.1 (Statgraphics 5.1, 2015).

Also ANOVA analyses were performed with a conversion of the damage level factors from a dummy variable to a qualitative variable of 7 categories, where each category represents the percentage of presence of that colour calculated as $\mathrm{Y}=\left(\mathrm{X}(\mathrm{c}) \mathrm{ij}_{\mathrm{ij}} \mathrm{x} 100\right) / 16$. The following grading is used: $0 \%=\mathrm{Y}$, $0<\mathrm{Y} \leq 5 \%, 5<\mathrm{Y} \leq 25 \%, 25<\mathrm{Y} \leq 50 \%, 50<\mathrm{Y} \leq 75 \%, 75<\mathrm{Y}<100 \%, \mathrm{Y}=100 \%$.

The goal is to understand the relationship between the height (and the horizontal) variable and the various stages of damage, to determine whether damage stages are related to the position on the wall. For this, ANOVA analyses were performed with height and column (quantitative variable of the horizontal) as dependent variable, respectively.

It is important to distinguish between walls, as these have different orientations as well as previous restoration works. For this, two different approaches have been used, perform ANOVA considering the wall factor (which takes the value 3 or 4 depending on the wall) and, secondly, make separate ANOVAs for each wall to further evaluation of certain interactions.

On the other hand, ANOVA analyses were performed considering the damage stage variables (colours) as dummy variables (0/1) and as categorical variables (7 levels).

Let us be $\mathrm{X}_{\mathrm{ij}}$, row $i$ of column $j$, which is composed of 16 elements of $2.5 \mathrm{~cm} \times 2.5 \mathrm{~cm}$. Thus, the interpretation of the ANOVA results in the case where the dependent variable is the height is the following: the average height of $\mathrm{X}_{\mathrm{ij}}$ (for every $j$ ), depending on the presence or absence of a particular damage stage (dummy variable) or the percentage of presence of such damage stage (categorical variable). Just as in the case where the dependent variable is the column.

The most relevant results are shown in the following subsections.

\section{RESULTS AND DISCUSSION}

\subsection{Damage maps}

Two maps of damage have been performed, one for wall 3 (Figure 3) and another for wall 4 (Figure 4). Through visual assessment of these maps simple conclusions can be drawn. The presence of more cracks in wall 3 (not restored) as well as that the original fresco closest to the soil is lost in both walls is highlighted by the maps.

Fig. 3 Damage mapping of Wall 3 (facing to the west) of room 2. Legend of equivalence between the grey scale and numerical scale of damage stages is represented 


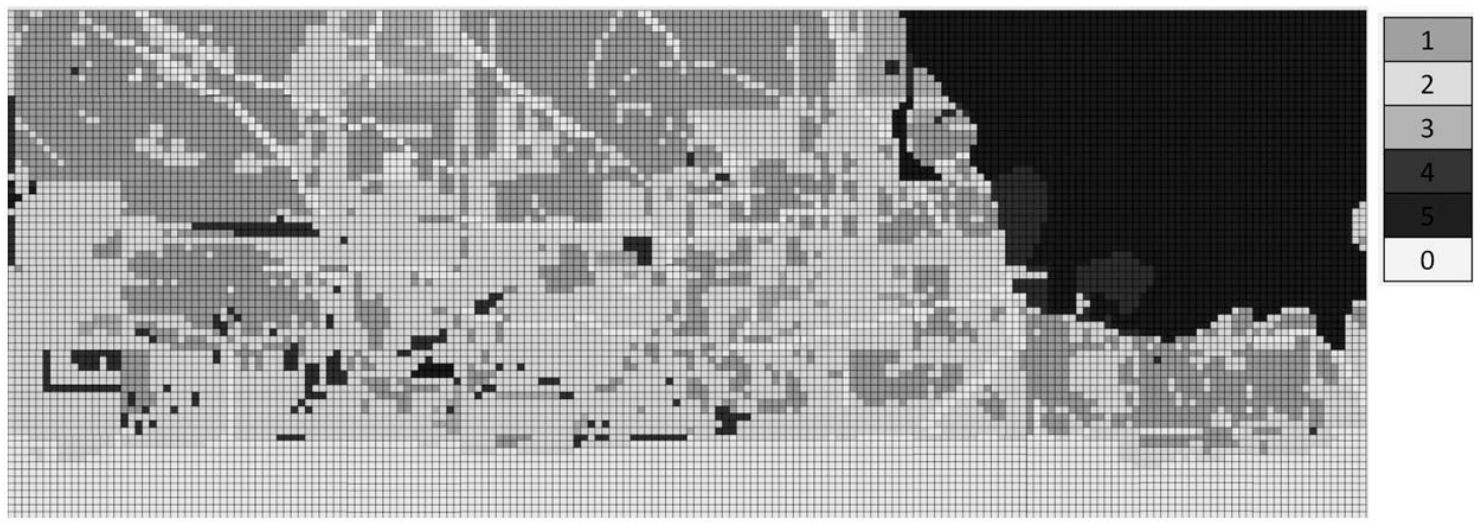

2 Fig. 4 Damage mapping of Wall 4 (facing to the north) of room 2. Legend of equivalence between the 3 grey scale and numerical scale of damage stages is represented

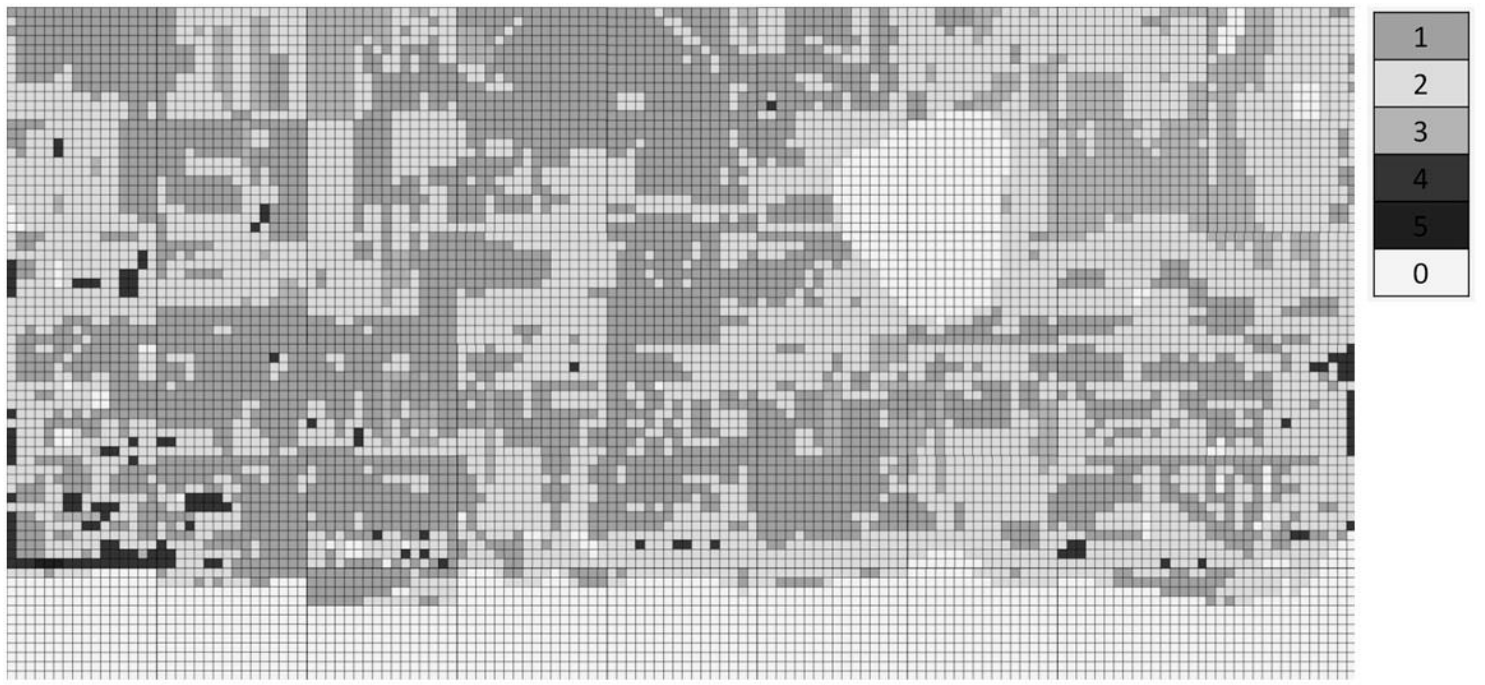

5 In contrast to mapping method (Hamamcioglu-Turan and Akbaylar 2011), the proposed method only 6 asses direct damage on pictorial layers of fresco, as this is directly related to damage by salts, without 7 going into other weathering forms: such as colour changes or plants colonization.

8 As in Staging system approach (Warke et al. 2003), stages of deterioration are previously defined in detail 9 based on the professional restorers expertise and assigned through visual inspection.

In contrast to both methods, our approach provides a damage score for each element of the mesh, this is for $2.5 \mathrm{~cm}$ x $2.5 \mathrm{~cm}$ sections, without losing the detail information of the differences inherent to a wall, which may be caused by differences in materials and microclimate to which it is are exposed.

As in the other methods, a final score of both the wall and the archaeological site can be easily calculated from a proportional average of the percentage of presence of each damage stage by assigning consecutive numerical values to the colour damage scale.

\subsection{Exploratory statistical analyses}

Colorimetric information from the damage map has been moved to a data matrix with qualitative and quantitative variables, as explained in Materials and methods section. Table 2 shows the summary of the descriptive statistics of the damage stages of both walls. 
Table 2. Descriptive statistical values for damage stage in wall 3 and 4. Descriptive statistics: total of cells of the colour per wall, percentage of cells of the colour per wall, average of cells of the colour in each row per wall, standard deviation of the cells of the colour per row and wall.

\begin{tabular}{|l|l|l|l|l|l|l|}
\hline & Green & Yellow & Orange & Red & Burgundy & White \\
\hline Wall 3 & & & & & & \\
\hline Total cells & 3496 & 4773 & 347 & 396 & 2317 & 2491 \\
\hline Percentage over the total (\%) & 25.3 & 34.5 & 2.5 & 2.9 & 16.8 & 18.0 \\
\hline Average & 4.1 & 5.5 & 0.4 & 0.5 & 2.7 & 2.9 \\
\hline Stand. Dev & 5.0 & 5.4 & 1.7 & 1.5 & 5.7 & 5.5 \\
\hline Wall 4 & & & & & & \\
\hline Total & 3461 & 4190 & 710 & 126 & 3 & 1877 \\
\hline Percentage over the total (\%) & 33.4 & 40.4 & 6.9 & 1.2 & 0.03 & 18.1 \\
\hline Average & 5.3 & 6.5 & 1.1 & 0.2 & 0.00 & 2.9 \\
\hline Stand. Dev & 5.2 & 4.9 & 2.5 & 0.9 & 0.1 & 5.6 \\
\hline
\end{tabular}

4

Table 2 highlights that the percentage of cells with a White damage stage coincides in both walls $(18.0 \approx 18.1)$. However, there are differences for other damage stages. The most notable case is that of burgundy, representing a $16.8 \%$ in wall 3 and is virtually non-existent in wall $4(0.03 \%)$, representing a difference of $99.8 \%$. For the rest of categories the percentage difference between walls is as follows: $24.2 \%$ green, $14.5 \%$ yellow, $63.4 \%$ orange, and $57.5 \%$ red.

However, note that if each stage damage is considered as a categorical variable of 7 levels $(Y=(X(c) i j ~ x$ 100)/16; with levels: $0 \%=\mathrm{Y}, 0<\mathrm{Y} \leq 5 \%, 5<\mathrm{Y} \leq 25 \%, 25<\mathrm{Y} \leq 50 \%, 50<\mathrm{Y} \leq 75 \%, 75<\mathrm{Y}<100 \%$, $\mathrm{Y}=100 \%$ ) all damage stage are in the same range, except for the orange and burgundy.

Bivariate correlation analyses have also been performed. Some damage stage pairs exhibit significant correlation, although in small amounts, with correlation coefficients for the case of wall 3 ranging from $\mathrm{r}=0.12$ y $\mathrm{r}=0.44$ ( $\mathrm{p}$-value $<0.001$ ). It seems that height has a significant relationship with damage stages, although of different intensity depending on the stage. The best correlation is presented for height and White damage stage $(\mathrm{r}=-0.5963$, $\mathrm{p}$-value $<0.0001)$. The conclusions are similar to the wall 4 .

Since, despite significant, correlation coefficients are generally lower than 0.5 , the information given by these analyses is interesting but can be improved with others to better characterize the damage state of the walls and the relationship between variables. Especially the relationship of the different damage stages with height justifies the use of height as dependent variable in an analysis of variance.

\subsection{Analysis of Variance (ANOVA)}

\subsubsection{Height as dependent variable in ANOVA}

Table 3 shows the results for the significant factors, both main effects and interactions, for the ANOVA analysis with height as dependent variable and damage stage factors (dummy 0/1) and wall (qualitative variable) as independent variables. In the figures, Least Square Difference (LSD) intervals are depicted for significance assessment.

Table 3. Significant factors ( $\mathrm{p}$-value<0.05), ANOVA height as dependent variable and damage stage (dummy) and wall as independent factors.

\begin{tabular}{|c|c|c|c|c|c|}
\hline Variable & $\begin{array}{l}\text { Sum } \\
\text { Squares }\end{array}$ & $\begin{array}{l}\begin{array}{l}\text { Freedom } \\
\text { degrees }\end{array} \\
\text { degre }\end{array}$ & $\begin{array}{l}\text { Mean } \\
\text { Square }\end{array}$ & F-Coeficient & P-Value \\
\hline \multicolumn{6}{|c|}{ MAIN EFFECTS } \\
\hline Orange & 43925.6 & 1 & 43925.6 & 32.00 & 0.0000 \\
\hline Red & 29187.6 & 1 & 29187.6 & 21.26 & 0.0000 \\
\hline \multicolumn{6}{|c|}{ INTERACTIONS } \\
\hline Wall * Green & 53673.0 & 1 & 53673.0 & 39.10 & 0.0000 \\
\hline
\end{tabular}




\begin{tabular}{|l|l|l|l|l|l|}
\hline Wall * Yellow & 10719.0 & 1 & 10719.0 & 7.81 & 0.0052 \\
\hline Wall * Orange & 14688.3 & 1 & 14688.3 & 10.70 & 0.0011 \\
\hline Wall * Red & 10277.7 & 1 & 10277.7 & 7.49 & 0.0062 \\
\hline Wall * White & 13988.3 & 1 & 13988.3 & 10.19 & 0.0014 \\
\hline Green * Yellow & 13120.1 & 1 & 13120.1 & 9.56 & 0.0020 \\
\hline Green * Orange & 9636.77 & 1 & 9636.77 & 7.02 & 0.0081 \\
\hline Green * Burgundy & 32010.0 & 1 & 32010.0 & 23.32 & 0.0000 \\
\hline Yellow * Orange & 7163.06 & 1 & 7163.06 & 5.22 & 0.0224 \\
\hline Yellow * Burgundy & 5880.16 & 1 & 5880.16 & 4.28 & 0.0385 \\
\hline Yellow * White & 26886.9 & 1 & 26886.9 & 19.58 & 0.0000 \\
\hline Orange * White & 54135.6 & 1 & 54135.6 & 39.43 & 0.0000 \\
\hline Burgundy * White & 6716.76 & 1 & 6716.76 & 4.89 & 0.0270 \\
\hline RESIDUALS & $2.03592 \mathrm{E} 6$ & 1483 & 1372.84 & & \\
\hline $\begin{array}{l}\text { TOTAL } \\
\text { (CORRECTED) }\end{array}$ & $4.08041 \mathrm{E} 6$ & 1511 & & & \\
\hline
\end{tabular}

1

2 Fig. 5 Main effects on ANOVA with dependent variable height, LSD intervals 95\%. A) factor orange, B) factor red

a)

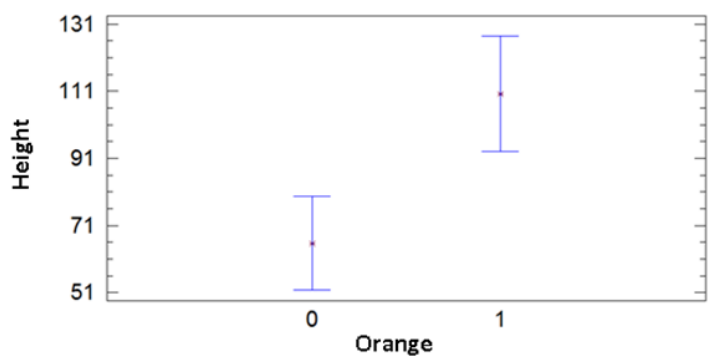

b)

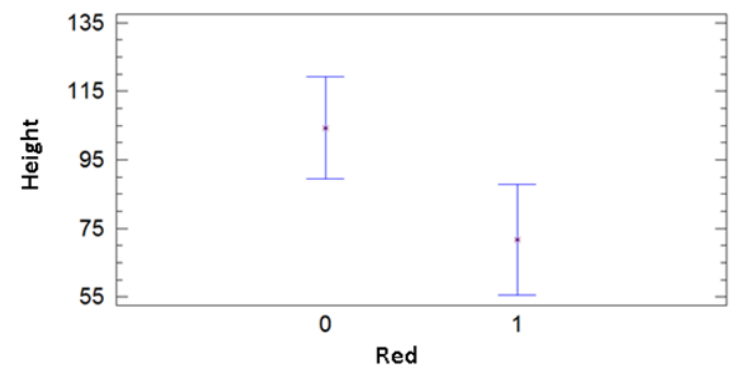

5 Note that the presence of orange stage in $X_{\mathrm{ij}}$ increases the average height of $\mathrm{X}_{\mathrm{ij}}$ (Figure 5.a), implying that 6 the orange damage stage is located at medium to high height (mean $=110.21 \mathrm{~cm}$, standard error $=12.38$ $7 \mathrm{~cm}$ ). In contrast, the presence of red colour in $\mathrm{X}_{\mathrm{ij}}$ reduces the average height of $\mathrm{X}_{\mathrm{ij}}$, so this damage stage is an average height of $71.66 \mathrm{~cm}$ (standard error $=11.62 \mathrm{~cm}$ ), in low-mid areas of wall (Figure 5.b).

Pay attention to the interaction between damage stage and wall factor. The interaction between wall and green stage indicates that the effect of the presence of green in $\mathrm{X}_{\mathrm{ij}}$ depends on the studied wall. In wall 3 , the presence of green stage increases the average height (green stage is located in the upper half of the monitored area), however in wall 4 presence of green stage decrements average height (green is found in the lower half of the monitored area). Green stage is placed at an average height of $113.26 \mathrm{~cm}$ (standard error $=6.78 \mathrm{~cm})$ in wall 3 and $58.36 \mathrm{~cm}($ standard error $=20.48 \mathrm{~cm})$ in wall 4 (Figure 6).

In the case of orange damage stage, the presence of orange damage stage increases the average height of $\mathrm{X}_{\mathrm{ij}}$ in wall 3 and 4, reaching the same average height (LSD intervals overlap). In the case of red damage stage, the presence of orange stage decreases the average height of $\mathrm{X}_{\mathrm{ij}}$ on both walls, although somewhat more pronounced in wall 4 , reaching an average height of $123.21 \mathrm{~cm}$ (standard error $=7.71 \mathrm{~cm}$ ) in wall 3 , and $97.20 \mathrm{~cm}$ (standard error $=21.31 \mathrm{~cm}$ ) in wall 4 .

Regarding interactions between levels of damage stage, the most interesting conclusions for the average height of $\mathrm{X}_{\mathrm{ij}}$ are obtained for wall 3 and the interaction of the following damage stages: green and orange $($ F-coeficient $=18.26$, P-value $<0.0001)$, yellow and orange $($ F-coeficient $=5.97, \mathrm{P}$-value $<0.02)$ and orange and white $(\mathrm{F}$-coeficient $=52.86$, P-value $<0.0001)$.

24 The interpretation of these interactions is as follows. The average height $\mathrm{X}_{\mathrm{ij}}$ where green and orange damage stage converge $($ mean $=121.38 \mathrm{~cm}$, standard error $=10.89 \mathrm{~cm}$ ) is lower than the average height 
where the orange occurs in the absence of green $(141.82 \mathrm{~cm}$, standard error $=9.66 \mathrm{~cm})$ and larger than the average height where green is given in the absence of orange $(98.06 \mathrm{~cm}$, standard error $=6.26 \mathrm{~cm})$. It occurs equally in the case of the interaction of yellow and orange damage stage (Figure 6.a).

4 The interaction between orange and white damage stage is different (Figure 6.b). The average height $X_{\mathrm{ij}}$ 5 that blends orange and white damage stage $(157.38 \mathrm{~cm}$, standard error $=12.13 \mathrm{~cm})$ is significantly higher 6 than the average height where there are those colours in the absence of the other $([89.50 \mathrm{~cm}, 122.14 \mathrm{~cm}]$ 7 for orange, [59.03 cm, $93.08 \mathrm{~cm}$ ] for white). The average height of white damage stage is conditioned by 8 the fact that this damage stage is easily found on the lower parts of both walls, however it is noticeable 9 that in the case of wall 3 is also dispersed in the form of cracks in the entire height of the wall, and one of 10 these cracks crosses one of the two Intonachino/Intonaco layer areas (orange damage stage) of the top of 11 the monitored area, (Figure 3).

12 Fig. 6 ANOVA analysis with height as dependent variable, for wall 3, with 95\% LSD intervals. A) Interaction between orange and yellow factors, B) interaction between orange and white factors
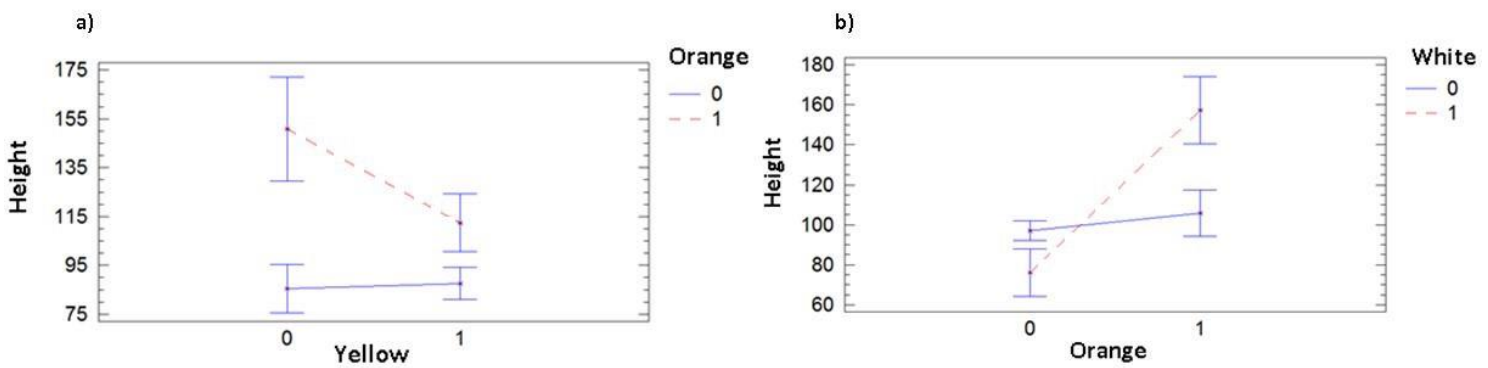

On the other hand, considering damage stage factors as categorical variables of 7 levels, the most notable results are given for red damage stage (F-coeficient=7.33, P-value $<0,0001)$ and white damage stage $(\mathrm{F}$ coeficient=18.21, P-value<0,0001).

For red damage the information given is not relevant, since significant differences in height are given for $\mathrm{X}_{\mathrm{ij}}$ with a percentage of involvement of this level of damage stage from the 76-99\% (Figure 7. a), but this category has a frequency equal to 1 in this wall, and the average height of $\mathrm{X}_{\mathrm{ij}}$ does not represent the real presence of red damage stage on both walls.

In the case of white damage stage (Figure 7.b) significant differences exist for the category of $100 \%$, which is always in the lowest areas on both walls (average height $\mathrm{X}_{\mathrm{ij}}=21.87 \mathrm{~cm}$, standard error $=28.54$ $\mathrm{cm}$ ) because these are cemented by previous interventions and without frescoes remains. Also, it seems remarkable (but not significant at $95 \%$ since the LSD intervals slightly overlap) the difference for the category 76-99\%, given at an average height of $59.51 \mathrm{~cm}$ (standard error= $27.89 \mathrm{~cm}$ ). The other categories take place at an average height of $[60.38,160] \mathrm{cm}$. This relation between white damage stage and height seems to have its origin in the higher levels of relative humidity in low areas of the wall by soil moisture contribution (Merello et al. 2012, 2013).

Fig. 7 Main effects for ANOVA with dependent variable height, for both walls, LSD intervals of $95 \%$ 
a)
2

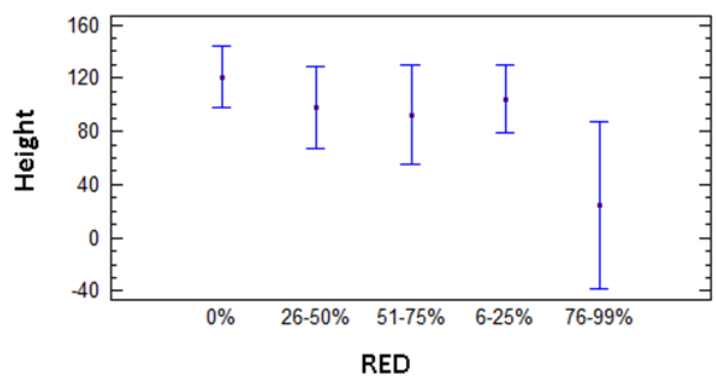

\subsubsection{Column as dependent variable in ANOVA}

b)

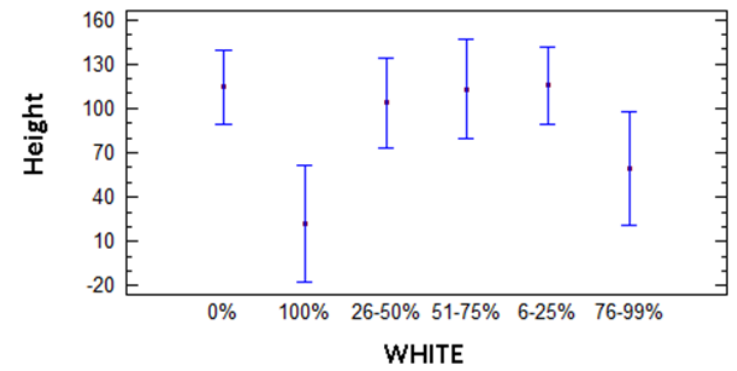

Let us be column $j$ of $\mathrm{X}_{\mathrm{ij}}$ the dependent variable in the ANOVA analysis. As for variable height, for column variable all possible combinations have been made.

For the case where stage damage factors are considered as dichotomous variables, the interaction between Green and Wall factors (F-coeficient=17.59, P-value<0.0001) and between wall and yellow (Fcoeficient=8.34, P-value $<0.005)$ is highlighted. The first interaction indicates that the effect of the presence of green damage stage in $\mathrm{X}_{\mathrm{ij}}$ depends on the studied wall. The presence of green occurs in average in column 6.58 (Standard error=0.47, Figure 8.a) in Wall 3, while in wall 4 this damage stage takes place in average at the left end of the wall (mean $=1$, Standard error $=1.43)$. These dissimilarities may be due to differences in the orientation and the effect of the windows and the door that leads to a difference in temperature and humidity of both walls.

In the case of yellow damage stage, the presence of this stage damage occurs in average at column 6.89 (standard error $=0.35$, right half of the wall) in wall 3 (Figure 8.b), while in wall 4 it is placed in average at column 2.8 (Standard error $=1.42$, left half of the wall).

Fig. 8 ANOVA interactions for analysis with column as dependent variable, Wall factor and damage stage factors as dichotomous variables, with LSD intervals 95\%. A) Interaction between green and wall. B) Interaction between wall and yellow

a)

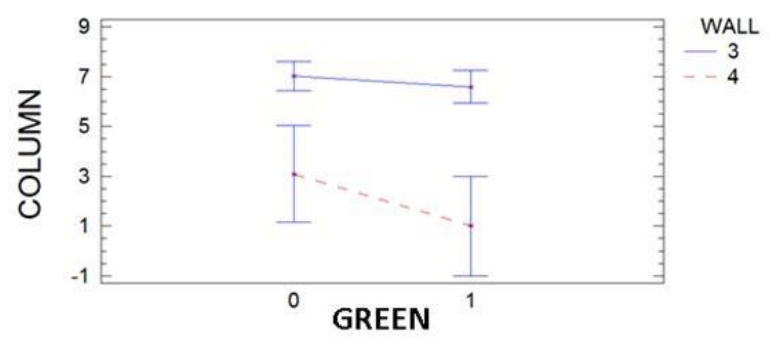

b)

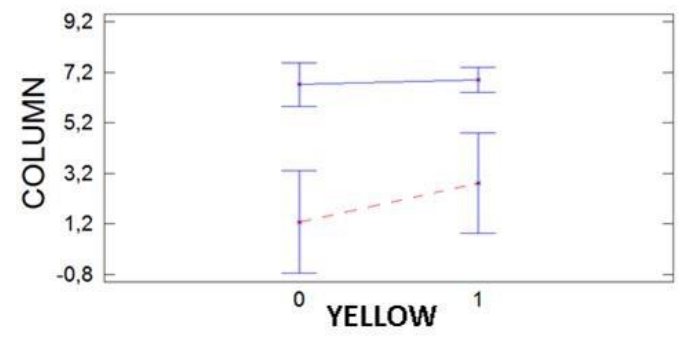

On the other hand, considering damage stage factors as categorical variables of 7 levels, the most noticeable results are given for red factor (F-coeficient $=8.52$, P-value $<0,0001$ ) and burgundy stage damage (F-coeficient=16.26, P-value<0,0001).

In the case of red damage stage (Figure 9.a), significant differences on variable column are find for $\mathrm{X}_{\mathrm{ij}}$ with a 76-99\% of involvement of this level of damage stage, therefore it takes place at the central area of both walls $($ mean $=6.05$, standard error $=3.24$, frequency $=1$ ), since the presence of this category of this factor decreases the average column in $\mathrm{X}_{\mathrm{ij}}$. However, no robust conclusions can be written as the frequency of this interval is equal to 1 .

In the case of burgundy damage stage (Figure 9.b) the differences are significant for category of $0 \%$, since the presence of this category decreases the average column in $\mathrm{X}_{\mathrm{ij}}$, showing that areas with no 
material are normally placed at the right of the wall. Note that the average column for an affectation of $51-75 \%$ (similar results for 76-99\%) is 11.16 (standard error =1.84). As 11.16 is bigger than 9 , which are

3 the columns of wall 4 , this points to wall 3 and the large brick missing at the right side.

4 Fig. 9 ANOVA main effects for analysis with column as dependent variable, data from both walls, LSD 5 intervals 95\%, and categorical damage stage factors of 7 levels. A) red damage stage, B) burgundy 6 damage stage

a)

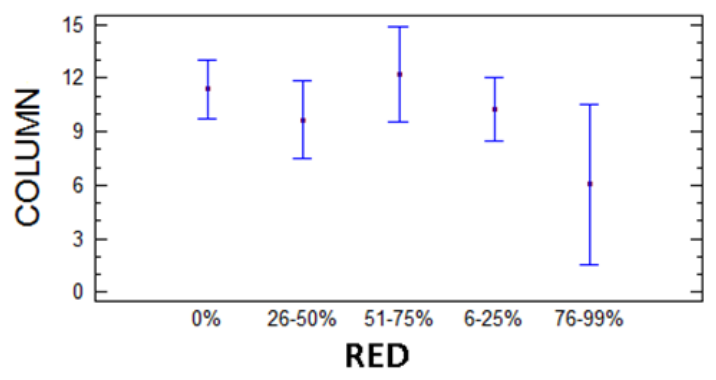

b)

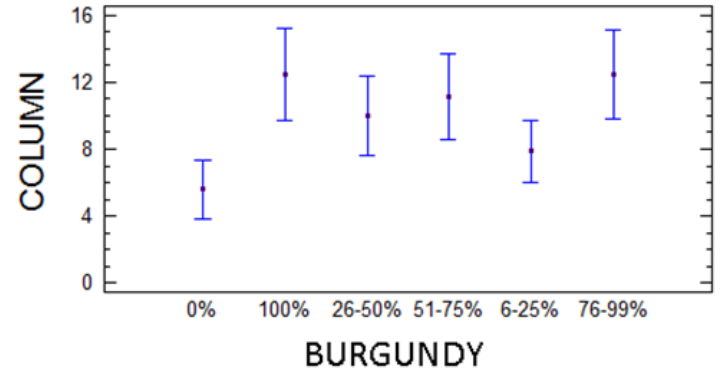

7

8

9

10

11

12

13

14

15

The above results show how is possible to draw significant conclusions about the damage caused by salt efflorescences in frescoes as well as its relationship with the morphology of the wall or other more causal variables related to these.

On the one hand, and based on image recognition technology, nowadays some authors are working on the development of non-invasive diagnosis of frescoes degradation through the detection of areas with colours deterioration on them (Guarneri et al. 2014). Our proposal is similar, since damage stage is evaluated cell by cell, but based on visual inspection. Our methodology is less automated but of a simpler and direct application for restorers and curators. Furthermore, our methodology implies the quantification of these damage stages and building a data matrix which allows crossing this data with other qualitative (orientation, etc.) or quantitative variables (RH, temperature, light, etc.) achieving further explanation of the causes of degradation.

In connection with this, other authors (O'Brien 1990) analyse which variables have an effect on the salt erosion using for this the design of experiments. Our methodology favours this kind of studies in places where it is not possible to make an experiment and yet it is very important to know in situ the different amount of salt erosion and its possible causes, this is the case of frescoes in archaeological sites.

\section{CONCLUSIONS}

The methodology proposed in this paper has proved useful in quantifying and empirically demonstrating significant differences between different damage stages produced by salts and their relationship with the morphological characteristics of the analysed wall. In contrast to normal damage mapping procedures by visual inspection, our approach is able to quantify more accurately because the assessment is performed on a grid with cells of $2.5 \mathrm{~cm} \times 2.5 \mathrm{~cm}$ and assigning a stage of damage to each cell.

After defining six stages of damage, a colorimetric map of damage has been performed for each wall. These maps allow a fast evaluation and guidance for restorers and curators as well as for an accurate budgeting of restoration work.

The analysis of variance (ANOVA) conducted on data matrices obtained from the quantification of the damage stage affectation per walls, reflected significant differences for the height and horizontal axis (column). Are noticeable those differences in height, especially for white damage stage, which are mainly caused by the contribution of soil moisture. On the other hand, differences in column may be attributed to differences in wall orientation and the presence of windows. 
However, the causes of these differences have not been analysed. This justifies the interest and future use of the proposed technique to cross the obtained data with other variables different to the morphological but related to these, as for example microclimate variables (temperature and humidity), materials (original material degradation and restoration materials) or salts analytical.

As far as the authors know, this is first time that qualitative-quantitative data obtained from damage mapping in frescoes are analysed by ANOVA and reported.

\section{Conflict of interest}

The authors declare that they have no conflict of interest.

\section{REFERENCES}

Arnold A, Zehnder K (1996) Monitoring wall paintings affected by soluble salts. In: Cather S (ed) The Conservation of Wall Paintings, 2nd edn. Courtauld Institute of Art and the Getty Conservation Institute, London, pp 103-136.

Goudie AS, Viles HA (1997) Salt weathering hazards, Wiley, London.

Guarneri M, Danielis A, Francucci M, De Collibus MF, Fornetti G, Mencattini A (2014) 3D remote colorimetry and watershed segmentation techniques for fresco and artwork decay monitoring and

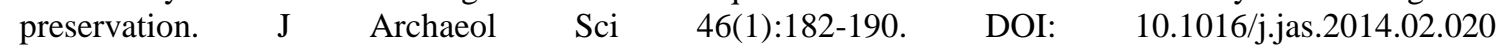

Hamamcioglu-Turan M, Akbaylar I (2011) Documentation of historic structures for the assessment of heritage characteristics. J Archit Plan Res

Merello P, García-Diego FJ, Zarzo M (2012) Microclimate monitoring of Ariadne's house (Pompeii, Italy) for preventive conservation of fresco paintings. Chem Cent J 6:145. DOI: 10.1186/1752-153X-6145 Merello P, García-Diego FJ, Zarzo M (2013) Evaluation of corrective measures implemented for the preventive conservation of fresco paintings in Ariadne's house (Pompeii, Italy). Chem Cent J 7(1):87. DOI:

$10.1186 / 1752-153 X-7-87$

Myra J, Giesena A, Ungb P, Warkec A, Christgenb B, Mazela AD, Grahamb DW (2014) Condition assessment and preservation of open-air rock art panels during environmental change. J Cult Herit 15:49_ 56. DOI: 10.1016/j.culher.2013.01.013

Nevin A, Melia JL, Osticioli I, Gautier G, Colombini MP (2008) The identification of copper oxalates in a 16th century Cypriot exterior wall painting using micro FTIR, micro Raman spectroscopy and Gas Chromatography-Mass Spectrometry J Cult Herit 9:154-161. DOI: 10.1016/j.culher.2007.10.002.

O'Brien P (1990) An experimental study of the effects of salt erosion on pottery. J Archaeol Sci 17(4):393-401. DOI: 10.1016/0305-4403(90)90004-O.

Pérez MC, Garcia-Diego FJ, Merello P, D’Antoni P, Fernández Navajas A, Ribera i Lacomba A, Ferrazza L, Pérez-Miralles J, Baró JL, Merce P, D’Antoni H, Curiel J (2013) Ariadne's house (Pompeii, Italy) wall paintings: A multidisciplinary study of its present state focused on a future restoration and preventive conservation. Mater Construcc 63(311):449-467. DOI: 10.3989/mc.2012.00812.

Pesando F (1997) Domus: edilizia privata e società pompeiana fra III e I secolo a.C., “L’Erma” di Bretschneider, Rome.

Pesando F (2007) La Casa de Ariadna de Pompeya: redescubrimiento de una domus. In: Ribera A, Olcina M, Ballester C (ed) Pompeya bajo Pompeya, Las excavaciones en la Casa de Ariadna. Museo Arqueológico Provincial de Alicante (MARQ), Valencia, pp 21-23.

Rodriguez-Navarro C, Doehne E (1999) Salt weathering: influence of evaporation rate, supersaturation and crystallization pattern. Earth Surf Process Landf 24:191-209. DOI: 10.1002/(SICI)1096- 


\section{7(199903)24:3<191::AID-ESP942>3.0.CO;2-G}

Ruiz-agudo E, Lubelli B, Sawdy A, Van Hees R, Price C, Rodriguez-Navarro C (2011) An integrated methodology for salt damage assessment and remediation: The case of San Jerónimo Monastery (Granada, Spain). Environ Earth Sci 63(7):1475-1486. DOI: 10.1007/s12665-010-0661-9

Statgraphics Software 5.1. Available online. http://www.statgraphics.net/. Accessed 18 March 2015.

Warke PA, Curran JM, Turkington AV, Smith BJ (2003) Condition Assessment for Building Stone Conservation: A Staging System Approach. Build Environ 38:1113-1123. DOI: 10.1016/S03601323(03)00085-4.

Weritz F, Kruschwitz S, Maierhofer C, Wendrich A (2009) Assessment of moisture and salt contents in brick masonry with microwave transmission, spectral-induced polarization, and laser-induced breakdown spectroscopy. Int J Archit Herit 3(2):126-144. DOI: 10.1080/15583050802278992

Winkler EM (1994) Stone in architecture, Springer, Berlin Heidelberg.

Wüst R, Schlüchter C (2000) The origin of soluble salts in rocks of the Thebes mountains, Egypt: The damage potential to ancient Egyptian wall art. J Archaeol Sci 27(12):1161-1172. DOI: $2010.1006 /$ jasc. 1999.0550 


\section{Quantitative non-invasive method for salts efflorescences damage 2 evaluation in frescoes: Ariadne's House (Pompeii, Italy)}

3 P. Merello ${ }^{1,2}$, P. Beltrán ${ }^{2}$, F-J. García-Diego ${ }^{2,3, *}$.

41 Instituto Valenciano de Conservación y Restauración de Bienes Culturales (IVC+R). 5 Complejo Socio-Educativo de Penyeta Roja s/n. 12080 Castellón, Spain. Email: 6 palomamerello@outlook.com

$7 \quad{ }^{2}$ Department of Applied Physics. Universitat Politècnica de València. Av. de los Naranjos s/n. 46022 Valencia, Spain. Email: pbeltran@fis.upv.es (P. B.).

${ }^{3}$ Centro de Tecnologías Físicas. Universitat Politècnica de València, Av. de los Naranjos s/n. 46022 Valencia, Spain.

11 All authors contributed equally to this work.

12 * Author to whom correspondence should be addressed; fjgarcid@ upv.es (F-J. G-D).

Abstract: The preventive conservation is based on acting on the causes of deterioration of cultural heritage to minimize damage, extending its lifetime and minimizing the costs of restoration. In these terms, damage caused by salts is one of the main focuses of study in immovable heritage. In this paper a quantitative method of recording and assessment of damage in frescoes eaused by salt efflorescences is presented. Damage mapping has been performed with a colour scale of six values for two fresco paintings of two walls at Ariadne's House (Pompeii, Italy), subsequently this information has been transferred to a data matrix which and statistical analysis of Variance (ANOVA) has been applied . ANOVA results show significant differences for the vertical and the horizontal axis depending on the different stages of damage. These differences also depend on the wall, which may be due to intrinsic differences such as materials of different restorations, the orientation of the wall, etc. or extrinsic differences and variations in temperature and relative humidity, etc. This methodology may be used in the future to quantify the influence of different variables on the extent of the deterioration of the paint layer, salts damage as for example determine and monitor its correlation to salts analytics in a determined facing.

Keywords: damage mapping; preventive conservation; salt efflerescences; frescoes deterioration; ANOVA.

\section{Acknowledgments}

This work was partially supported by the Spanish Government (Ministerio de Economía y Competitividad) under projects HAR2013-47895-C2-1-P and HAR2013-47895-C2-2-P. This publication is part of the program of valorisation and combined resources of the I+D+i of VLC/CAMPUS and has been partially supported by the Ministry of Education, Culture and Sports as part of the program of international excellence campus (PAID 06-14). 


\section{INTRODUCTION}

2 Ariadne's House is one of the biggest stately domus of the private Pompeian architecture (1700 m2) and

3 is located in the "Regio" VII, insula 4 (Pompeii, Italy), located at the centre of the city, less than 100 4 meters from the forum (Pesando 2007). Ariadne's House was first excavated between 1832 and 1835 5 (Pesando 1997) and is still being excavated till nowadays. Four of its rooms still conserve frescoes, in 6 order to preserve them; these rooms were roofed in the 70's with transparent polycarbonate covers (Pérez 7 et al. 2013). Afterwards, it was determined by the analysis of data recorded in a microclimatic monitoring 8 campaign that these transparent roofs were causing a greenhouse effect and damaging the frescoes 9 (Merello et al. 2012)]. In 2009-2010 the covers were changed by opaque fibre-cement covers and, after a second monitoring campaign, it was determined that the thermo-hygrometric conservation conditions of the frescoes had been improved (Merello et al. 2013).

Preventive conservation is a work methodology that is based on controlling the possible deterioration causes of cultural heritage to prevent its occurrence. Currently, the importance of preventive conservation is well recognized, both in terms to prevent the deterioration of cultural heritage as, in economic terms, to reduce the cost of future corrective actions.

In the case of wall paintings, the deterioration process is determined by factors such as petrographical and chemical characteristics of the materials, presence of mineral salts and organic substances on the surfaces, air pollution, sunlight, temperature, water content of the surface, etc. (Arnold and Zehnder 1996; Nevin et al. 2008).

The determination of water and salt distribution in brickwork and stonework is a frequent problem in cultural heritage protection (Weritz et al. 2009), as salt weathering is a major decay mechanism affecting historic architecture and statuary as well as modern buildings and others (Goudie and Viles 1997; Winkler 1994; Rodriguez-Navarro and Doehne 1999; Ruiz-agudo et al. 2011). Special attention to the disintegration of wall paintings caused by salt efflorescences has been considered in other studies (Wüst and Schlüchter 2000).

Frescoes do not have an identical conservation state in its entirety expanse due to the different influence of atmospheric agents (temperature, relative humidity light, etc.), and original materials or those used in past restorations. Therefore, it is necessary to characterize their conservation status quantitative and in detail with a damage mapping. This map is of valuable interest to help the restorer in his work, to develop restoration budgets or to perform crossed analyses with other control data (such as thermo-hygrometric data).

There are two main methods of damage mapping commonly used in cultural heritage and, usually, based on visual inspection; the monument mapping method (Hamamcioglu-Turan and Akbaylar 2011) and a staging system approach (UAS method - Unit, Area, Spread) (Warke et al. 2003).

In mapping method, different weathering forms (e.g. cracks, loss of material, colour changes, plants colonization) are evaluated in a plane and a score based on their severity and extent is given to each one. Later, each weathering form is scored in each area, all scores are combined and a final score of the area (from 0-5) is given. Finally, a deterioration index is calculated for the entire monument as an average of the score in the different areas (Hamamcioglu-Turan and Akbaylar 2011).

Staging system approach stems from an analogy between cancer patients treatment and the conservation of stone structures (Warke et al. 2003). Stages of deterioration (usually 4 or 5) are defined in detail and assigned to each area (typically a façade) by various experts through visual inspection. The final score for each zone is obtained as the average of the scores assigned by the experts.

Both methods are similar, but mapping method is more global as it evaluates different weathering forms and calculates an overall deterioration score of the site. 
1 The quantitative results of the damage assessment are scarcely crossed later with other variables. In (Myra et al. 2014), the authors use staging system approach to quantify the level of deterioration. To determine how geochemical and physical descriptors correlate with stage, bivariate correlation analysis was performed on all data; only cations, often associated with soil salinity, significantly correlated with stage.

However, the weakness of both methods for statistical analysis is that the study area (a façade, a fresco, etc.) is considered as a whole (having a single quantitative value of damage) when performing crossed analysis with other variables, losing valuable information of the diversity within the same study area.

In the case of Ariadne's House, after the roof change, is necessary to quantify the current conservation state of the frescoes in order to analyse in the future how this change has affected them.

The aim of this paper is to propose a methodology for mapping salt damage in frescoes, in order to compare different walls, quantify damage and cross this data with data from temperature, relative humidity, light or salt analytics in future studies. The current conservation state of the Ariadne's House frescoes through a numerical damage scale is quantitatively documented, performing a visual colour mapping and translating it into a data matrix that encompasses the assessment of each cell of the grid in which the study area (wall) is divided. Subsequently, damage data and its relation to the morphological characteristics of the walls are statistically analysed.

\section{MATERIALS AND METHODS}

\subsection{Definition of salt damage stages}

From the knowledge and advice of different curators and conservators, as well as the common sense, a scale of 6 categories of frescoes degradation damage by salt efflorescence depending on the visible paint layer that reflects the current state of preservation of the fresco has been developed (Table 1).

Areas with previous restorations or presence of consolidating materials such as mortars etc. have been categorized with a particular stage as "white zones".

A colour scale, intended to reflect the outcome of the evaluation in a simple and visual colorimetric map, has been used.

Table 1. Damage stage definition.

\begin{tabular}{|l|l|l|}
\hline Colour & $\begin{array}{l}\text { Numerical } \\
\text { scale } \\
\text { equivalence }\end{array}$ & Damage definition \\
\hline Green & 1 & $\begin{array}{l}\text { Paint layer is visible and in good state of conservation. Different colours } \\
\text { can be easily identified. Best conservation state of the studied frescoes. }\end{array}$ \\
\hline Yellow & 2 & $\begin{array}{l}\text { Paint layer decay or presence of salts efflorescences. Remains of the paint } \\
\text { layer can be seen but the original density of the paint has been lost. } \\
\text { Restoration works for salt efflorescences removing involve superficial } \\
\text { cleaning by mechanical techniques. }\end{array}$ \\
\hline Orange & 3 & $\begin{array}{l}\text { Intonachino/Intonaco layer (Pérez et al. 2013) can be seen. The entire } \\
\text { paint layer is lost. }\end{array}$ \\
\hline Red & 4 & $\begin{array}{l}\text { Intonaco/Arriccio layer (Pérez et al. 2013) can be seen. The entire Paint } \\
\text { and Intonachino layers are lost. }\end{array}$ \\
\hline Burgundy & 5 & $\begin{array}{l}\text { Brick wall can be seen. Paint layer and Intonachino/Intonaco/Arriccio } \\
\text { layers are lost. }\end{array}$ \\
\hline White & 0 & Area with previous restoration. The restoration is visually noticeable. \\
\hline
\end{tabular}


1 The procedure for visual inspection of the damage eaused by salt efflorescence on the frescoes of Ariadne's House, is done through a detailed inspection of photographs of an equidistant partition of each

3 wall with a virtual mesh.

4 Inspection performed directly on photographs was chosen for three reasons. On one hand, this allows 5 recording a graphic documentation of the archaeological site which will be available in the future, and 6 would even allow performing the assessment work by a different expert.

7 On the other hand, lighting, contrast, etc., can be adjusted in the photographs, so that differences between 8 samples are homogenized and chromatic and luminance characteristics are the same during the whole 9 experiment. This will never be possible in on site assessment.

10 Finally, the photographic record allows damage assessment with a greater margin of time, avoiding bias 11 in the experiment attributable to long hours of work standing evaluation.

12 To take the pictures a Panasonic camera, model TZ10, with a resolution of 12.1 mega pixels has been 13 used. The photographs were taken during the 27th October 2014, between 10:30 and 13:00 hours.

14 To make the grid of the wall and the photographs of each element of the grid, two vertical metal supports 15 of $180 \mathrm{~cm}$, with a subdivision of its height in 6 sections and equidistant spacing between supports of 40 $16 \mathrm{~cm}$ were used. As a result, each element of the mesh, and thus each picture, is a wall section of $30 \times 40 \mathrm{~cm}$. 17 To assess damage in detail, each picture is divided using a grid of 192 elements $2.5 \mathrm{~cm} \times 2.5 \mathrm{~cm}(12$ 18 elements in the vertical x 16 elements in the horizontal).

19 The evaluation of the pictures was orderly conducted, per columns and per rooms at the monitor of a 20 computer, allowing zooming on the different elements of the mesh for an accurate assessment of the 21 damage stage.

In order to make the process of applying the methodology easier, two computer screens were used. One screen was used for the visual inspection of the zoomed image meanwhile the other showed the general image of the wall with a grid. Also, the needed settings of brightness, contrast and definition of the image were performed.

In this paper, two walls with frescoes of a roofed room (Figure 1) of Ariadne's House are evaluated. Wall 4 (Figure 2.b), facing to the north and restored in 2012, with measures of $450 \mathrm{~cm}$ (high) x $360 \mathrm{~cm}$ (width).

28 Monitored dimensions are $180 \mathrm{~cm}$ (height) x $360 \mathrm{~cm}$ (width). A total of 54 photos (6x9) were taken.

Wall 3 (Figure 2.a), facing to the west, has measures of $450 \mathrm{~cm} \mathrm{x} 480 \mathrm{~cm}$. Monitored dimensions are 180 $\mathrm{cm}$ (height) x $480 \mathrm{~cm}$ (width). A total of 72 (6x12) photos were taken.

The monitored height was $180 \mathrm{~cm}$ since above this height frescoes did not exist or were in a homogeneous conservation state. Lower parts of the walls are important to be studied as they have suffered more preventive conservation and restoration works, as well as possible effects of soluble salts from soil (which could be studied in future works).

Fig. 1 Map of Ariadne's house and monitored room (room 2) 


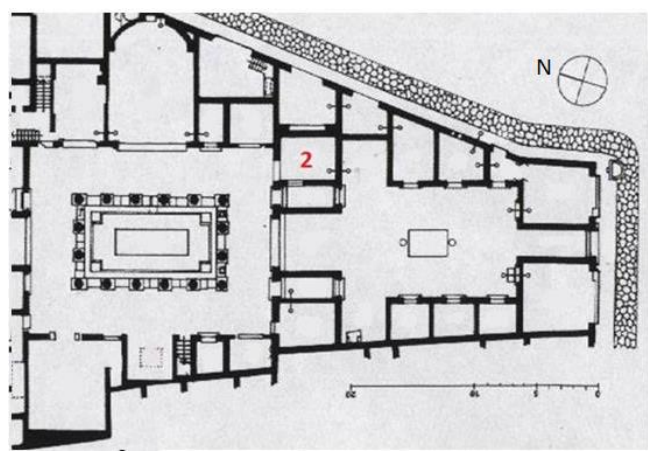

Fig. 2 A) Frescoes in wall 3 (facing to the west) of room 2. B) Frescoes in wall 4 (facing to the north) of room 2
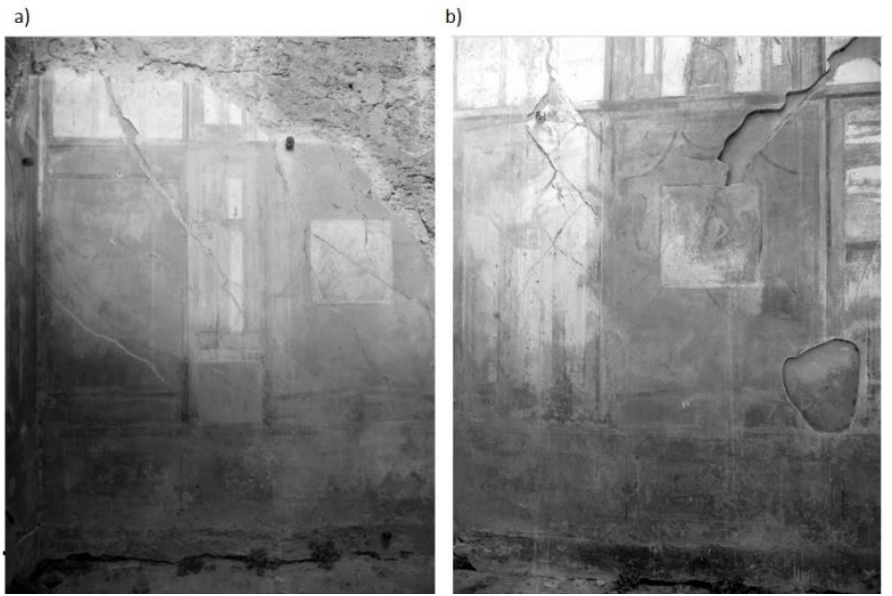

The sampling and monitoring units are defined as $X(c)_{i j}$, corresponding to the number of colour "c" elements of $2.5 \mathrm{~cm} \times 2.5 \mathrm{~cm}$ present in row (height) $i$ (i=\{1,..,72 $\}$ for both walls) of column (width) $j$ $(j=\{1, \ldots, 9\}$ for wall $4, j=\{1, \ldots, 12\}$ for wall 3$)$. Note that each row has a height of $2.5 \mathrm{~cm}$, while each column has a width of $40 \mathrm{~cm}$, since it is considered a priori that significant differences may be more in the vertical axis (rows) in the horizontal (column).

After transferring colorimetric information to a damage data matrix, there is a data matrix of $864 \times 9$ for wall 3; 864 observations (12 sample columns x 72 inspected items/column) and 9 variables (6 damage stages, row $i$, column $j$, row height $i$ ). For wall 4 there is a $648 \times 9$ data matrix; 648 observations ( 9 sample columns $x 72$ inspected items/column) and the same 9 variables.

Note that the assessment work, visual inspection of the photographs and mapping performed took 3-4 days.

\subsection{Analysis of Variance (ANOVA)}

To study the effect of the presence of the different salts damage levels (categorized as colours), different ANOVA models were tested for data recorded in 2014, considering the following factors: one factor for each damage level (dummy variables green, yellow, orange, red, burgundy and white, which take value 1 if $\mathrm{X}(\mathrm{c})_{\mathrm{ij}}>0$, and 0 otherwise) and wall (taking value 3,4). ANOVAs were performed using the software Statgraphics 5.1 (Statgraphics 5.1, 2015).

Also ANOVA analyses were performed with a conversion of the damage level factors from a dummy variable to a qualitative variable of 7 categories, where each category represents the percentage of presence of that colour calculated as $\mathrm{Y}=\left(\mathrm{X}(\mathrm{c})_{\mathrm{ij}} \mathrm{X} 100\right) / 16$. The following grading is used: $\mathrm{Y}=0 \%$, $0<\mathrm{Y} \leq 5 \%, 5<\mathrm{Y} \leq 25 \%, 25<\mathrm{Y} \leq 50 \%, 50<\mathrm{Y} \leq 75 \%, 75<\mathrm{Y}<100 \%, \mathrm{Y}=100 \%$. 
The goal is to understand the relationship between the height (and the horizontal) variable and the various stages of damage, to determine whether damage stages are related to the position on the wall. For this, ANOVA analyses were performed with height and column (quantitative variable of the horizontal) as

Fig. 3 Damage mapping of Wall 3 (facing to the west) of room 2. Legend of equivalence between the grey scale and numerical scale of damage stages is represented

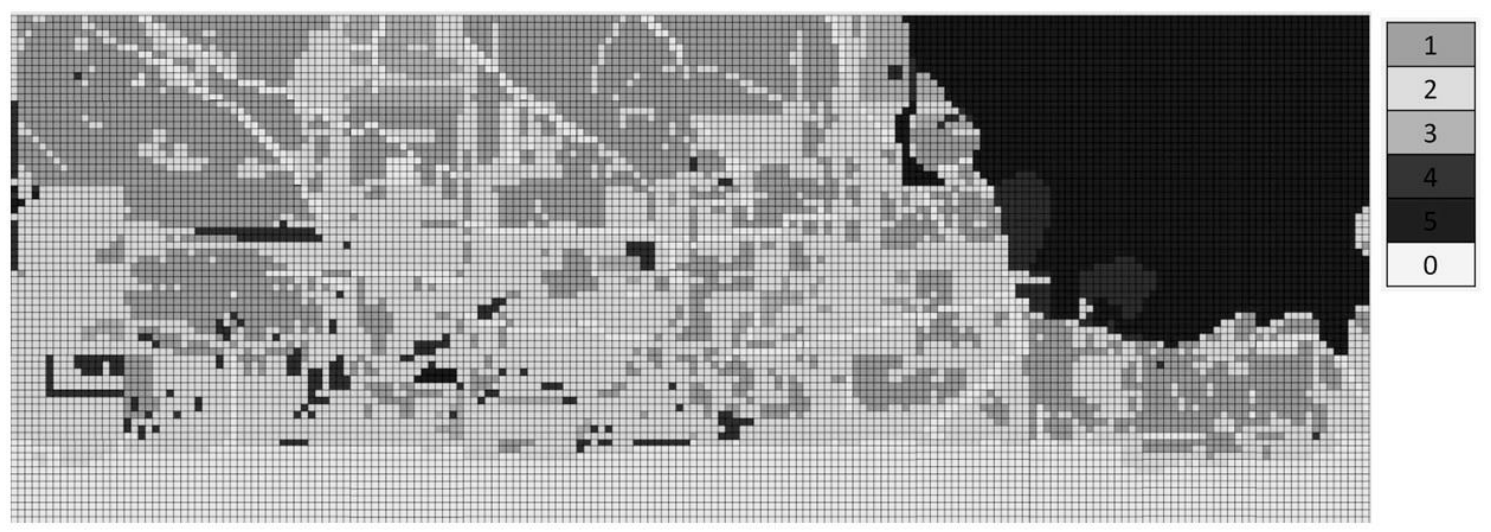

Fig. 4 Damage mapping of Wall 4 (facing to the north) of room 2. Legend of equivalence between the 


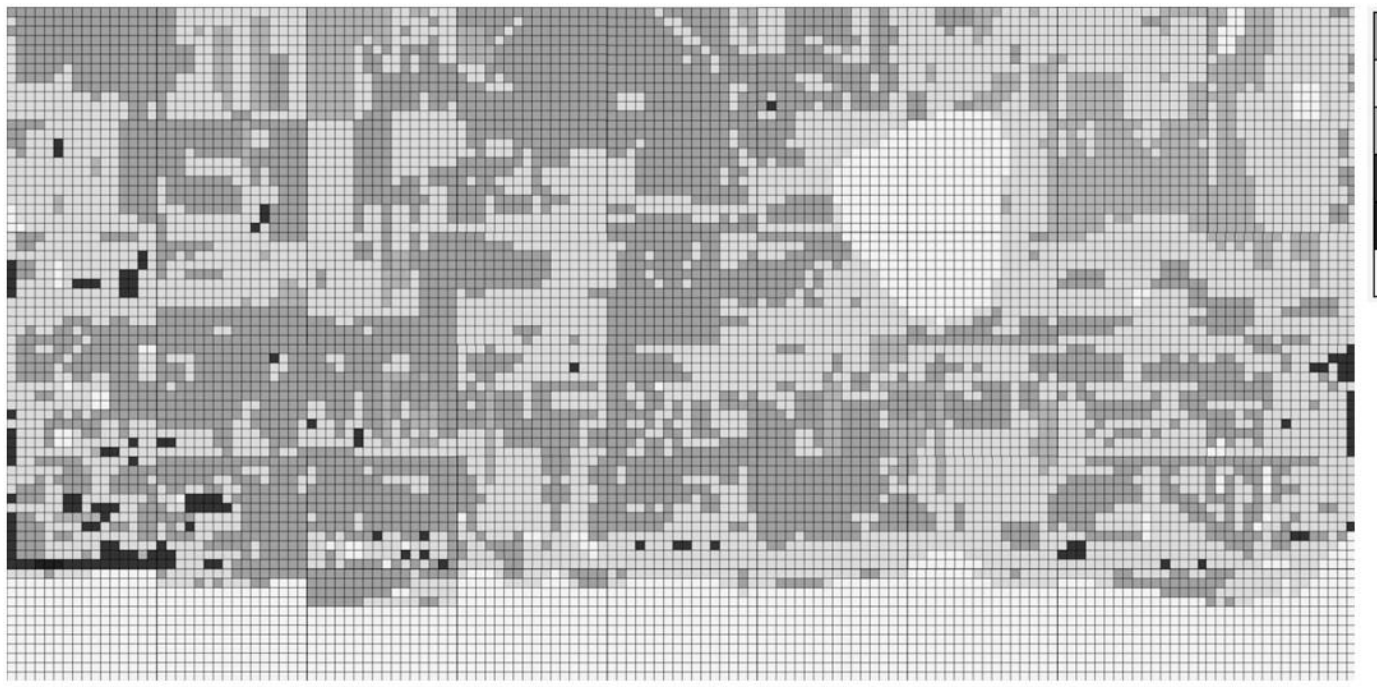

\begin{tabular}{|l|l|l|l|l|l|l|}
\hline & Green & Yellow & Orange & Red & Burgundy & White \\
\hline Wall 3 & & & & & & \\
\hline Total cells & 3496 & 4773 & 347 & 396 & 2317 & 2491 \\
\hline Percentage over the total (\%) & 25.3 & 34.5 & 2.5 & 2.9 & 16.8 & 18.0 \\
\hline Average & 4.1 & 5.5 & 0.4 & 0.5 & 2.7 & 2.9 \\
\hline Stand. Dev & 5.0 & 5.4 & 1.7 & 1.5 & 5.7 & 5.5 \\
\hline Wall 4 & & & & & & \\
\hline Total & 3461 & 4190 & 710 & 126 & 3 & 1877 \\
\hline Percentage over the total (\%) & 33.4 & 40.4 & 6.9 & 1.2 & 0.03 & 18.1 \\
\hline Average & 5.3 & 6.5 & 1.1 & 0.2 & 0.00 & 2.9 \\
\hline Stand. Dev & 5.2 & 4.9 & 2.5 & 0.9 & 0.1 & 5.6 \\
\hline
\end{tabular}

21 Table 2 highlights that the percentage of cells with a White damage stage coincides in both walls

In contrast to mapping method (Hamamcioglu-Turan and Akbaylar 2011), the proposed method only asses direct damage on pictorial layers of fresco, as this is directly related to damage by salts, without going into other weathering forms: such as colour changes or plants colonization.

As in Staging system approach (Warke et al. 2003), stages of deterioration are previously defined in detail based on the professional restorers expertise and assigned through visual inspection.

In contrast to both methods, our approach provides a damage score for each element of the mesh, this is for $2.5 \mathrm{~cm} \times 2.5 \mathrm{~cm}$ sections, without losing the detail information of the differences inherent to a wall, which may be caused by differences in materials and microclimate to which it is are exposed.

As in the other methods, a final score of both the wall and the archaeological site can be easily calculated from a proportional average of the percentage of presence of each damage stage by assigning consecutive numerical values to the colour damage scale.

\subsection{Exploratory statistical analyses}

Colorimetric information from the damage map has been moved to a data matrix with qualitative and quantitative variables, as explained in Materials and methods section. Table 2 shows the summary of the descriptive statistics of the damage stages of both walls.

Table 2. Descriptive statistical values for damage stage in wall 3 and 4. Descriptive statistics: total of cells of the colour per wall, percentage of cells of the colour per wall, average of cells of the colour in each row per wall, standard deviation of the cells of the colour per row and wall. 
1 burgundy, representing a $16.8 \%$ in wall 3 and is virtually non-existent in wall $4(0.03 \%)$, representing a difference of $99.8 \%$. For the rest of categories the percentage difference between walls is as follows:

$324.2 \%$ green, $14.5 \%$ yellow, $63.4 \%$ orange, and $57.5 \%$ red.

4 However, note that if each stage damage is considered as a categorical variable of 7 levels $\left(\mathrm{Y}=\left(\mathrm{X}(\mathrm{c})_{\mathrm{ij}} \mathrm{X}\right.\right.$ 5 100)/16; with levels: $0 \%=\mathrm{Y}, 0<\mathrm{Y} \leq 5 \%, 5<\mathrm{Y} \leq 25 \%, 25<\mathrm{Y} \leq 50 \%, 50<\mathrm{Y} \leq 75 \%, 75<\mathrm{Y}<100 \%, \mathrm{Y}=100 \%)$ all 6 damage stage are in the same range, except for the orange and burgundy.

7

8

9

10

11

12

Bivariate correlation analyses have also been performed. Some damage stage pairs exhibit significant correlation, although in small amounts, with correlation coefficients for the case of wall 3 ranging from $\mathrm{r}=0.12$ y r=0.44 ( $\mathrm{p}$-value<0.001). It seems that height has a significant relationship with damage stages, although of different intensity depending on the stage. The best correlation is presented for height and White damage stage $(r=-0.5963$, $\mathrm{p}$-value $<0.0001)$. The conclusions are similar to the wall 4.

Since, despite significant, correlation coefficients are generally lower than 0.5 , the information given by these analyses is interesting but can be improved with others to better characterize the damage state of the walls and the relationship between variables. Especially the relationship of the different damage stages with height justifies the use of height as dependent variable in an analysis of variance.

\subsection{Analysis of Variance (ANOVA)}

\subsubsection{Height as dependent variable in ANOVA}

Table 3 shows the results for the significant factors, both main effects and interactions, for the ANOVA analysis with height as dependent variable and damage stage factors (dummy 0/1) and wall (qualitative variable) as independent variables. In the figures, Least Square Difference (LSD) intervals are depicted for significance assessment.

Table 3. Significant factors ( $\mathrm{p}$-value $<0.05$ ), ANOVA height as dependent variable and damage stage (dummy) and wall as independent factors.

\begin{tabular}{|l|l|l|l|l|l|}
\hline Variable & $\begin{array}{l}\text { Sum } \\
\text { Squares }\end{array}$ & $\begin{array}{l}\text { Freedom } \\
\text { degrees }\end{array}$ & $\begin{array}{l}\text { Mean } \\
\text { Square }\end{array}$ & F-Coeficient & P-Value \\
\hline MAIN EFFECTS & 43925.6 & 1 & 43925.6 & 32.00 & 0.0000 \\
\hline Orange & 29187.6 & 1 & 29187.6 & 21.26 & 0.0000 \\
\hline Red & \multicolumn{5}{l|}{} \\
\hline INTERACTIONS & 53673.0 & 1 & 53673.0 & 39.10 & 0.0000 \\
\hline Wall * Green & 10719.0 & 1 & 10719.0 & 7.81 & 0.0052 \\
\hline Wall * Yellow & 14688.3 & 1 & 14688.3 & 10.70 & 0.0011 \\
\hline Wall * Orange & 10277.7 & 1 & 10277.7 & 7.49 & 0.0062 \\
\hline Wall * Red & 13988.3 & 1 & 13988.3 & 10.19 & 0.0014 \\
\hline Wall * White & 13120.1 & 1 & 13120.1 & 9.56 & 0.0020 \\
\hline Green * Yellow & 9636.77 & 1 & 9636.77 & 7.02 & 0.0081 \\
\hline Green * Orange & 32010.0 & 1 & 32010.0 & 23.32 & 0.0000 \\
\hline Green * Burgundy & 7163.06 & 1 & 7163.06 & 5.22 & 0.0224 \\
\hline Yellow * Orange & 5880.16 & 1 & 5880.16 & 4.28 & 0.0385 \\
\hline Yellow * Burgundy & 26886.9 & 1 & 26886.9 & 19.58 & 0.0000 \\
\hline Yellow * White & 54135.6 & 1 & 54135.6 & 39.43 & 0.0000 \\
\hline Orange * White & 6716.76 & 1 & 6716.76 & 4.89 & 0.0270 \\
\hline Burgundy * White & $2.03592 E 6$ & 1483 & 1372.84 & & \\
\hline RESIDUALS & $4.08041 E 6$ & 1511 & & & \\
\hline $\begin{array}{l}\text { TOTAL } \\
\text { (CORRECTED) }\end{array}$ & & & & \\
\hline
\end{tabular}

Fig. 5 Main effects on ANOVA with dependent variable height, LSD intervals 95\%. A) factor orange, B) 
a)
1

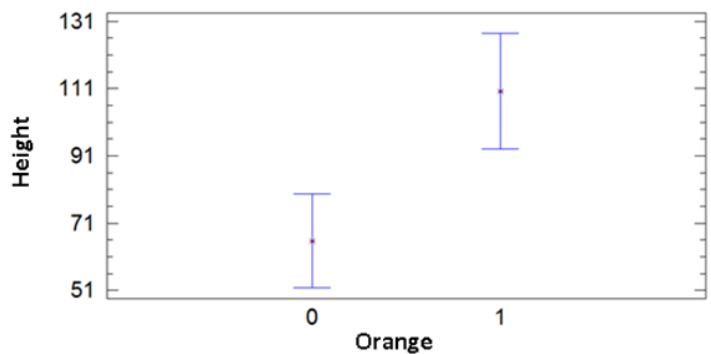

b)

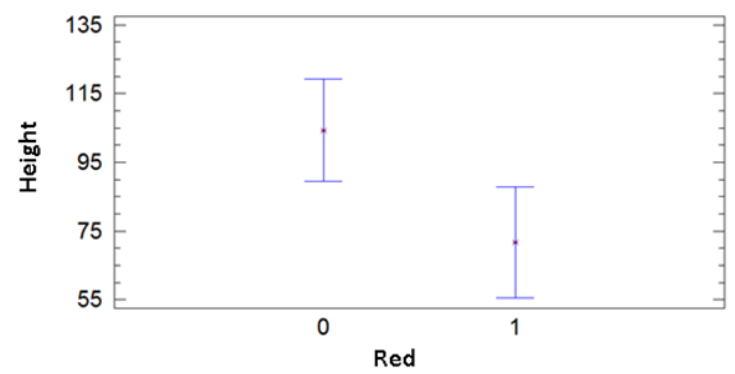

2 Note that the presence of orange stage in $X_{\mathrm{ij}}$ increases the average height of $X_{\mathrm{ij}}$ (Figure 5.a), implying that 3 the orange damage stage is located at medium to high height (mean $=110.21 \mathrm{~cm}$, standard error $=12.38$ $4 \mathrm{~cm}$ ). In contrast, the presence of red colour in $X_{\mathrm{ij}}$ reduces the average height of $X_{\mathrm{ij}}$, so this damage stage is an average height of $71.66 \mathrm{~cm}$ (standard error $=11.62 \mathrm{~cm}$ ), in low-mid areas of wall (Figure 5.b).

6 Pay attention to the interaction between damage stage and wall factor. The interaction between wall and 7 green stage indicates that the effect of the presence of green in $X_{i j}$ depends on the studied wall. In wall 3 , 8 the presence of green stage increases the average height (green stage is located in the upper half of the 9 monitored area), however in wall 4 presence of green stage decrements average height (green is found in the lower half of the monitored area). Green stage is placed at an average height of $113.26 \mathrm{~cm}$ (standard error $=6.78 \mathrm{~cm})$ in wall 3 and $58.36 \mathrm{~cm}($ standard error $=20.48 \mathrm{~cm})$ in wall 4 (Figure 6).

12 In the case of orange damage stage, the presence of orange damage stage increases the average height of $\mathrm{X}_{\mathrm{ij}}$ in wall 3 and 4, reaching the same average height (LSD intervals overlap). In the case of red damage stage, the presence of orange stage decreases the average height of $X_{i j}$ on both walls, although somewhat more pronounced in wall 4, reaching an average height of $123.21 \mathrm{~cm}$ (standard error $=7.71 \mathrm{~cm}$ ) in wall 3 , and $97.20 \mathrm{~cm}$ (standard error $=21.31 \mathrm{~cm}$ ) in wall 4 .

Regarding interactions between levels of damage stage, the most interesting conclusions for the average height of $\mathrm{X}_{\mathrm{ij}}$ are obtained for wall 3 and the interaction of the following damage stages: green and orange $($ F-coeficient $=18.26$, P-value $<0.0001)$, yellow and orange $($ F-coeficient $=5.97, \mathrm{P}$-value $<0.02)$ and orange and white $(\mathrm{F}$-coeficient $=52.86$, P-value $<0.0001)$.

The interpretation of these interactions is as follows. The average height $\mathrm{X}_{\mathrm{ij}}$ where green and orange damage stage converge $($ mean $=121.38 \mathrm{~cm}$, standard error $=10.89 \mathrm{~cm})$ is lower than the average height where the orange occurs in the absence of green $(141.82 \mathrm{~cm}$, standard error $=9.66 \mathrm{~cm})$ and larger than the average height where green is given in the absence of orange $(98.06 \mathrm{~cm}$, standard error $=6.26 \mathrm{~cm})$. It occurs equally in the case of the interaction of yellow and orange damage stage (Figure 6.a).

The interaction between orange and white damage stage is different (Figure 6.b). The average height $X_{\mathrm{ij}}$ that blends orange and white damage stage $(157.38 \mathrm{~cm}$, standard error $=12.13 \mathrm{~cm})$ is significantly higher than the average height where there are those colours in the absence of the other $([89.50 \mathrm{~cm}, 122.14 \mathrm{~cm}]$ for orange, [59.03 cm, $93.08 \mathrm{~cm}$ ] for white). The average height of white damage stage is conditioned by the fact that this damage stage is easily found on the lower parts of both walls, however it is noticeable that in the case of wall 3 is also dispersed in the form of cracks in the entire height of the wall, and one of these cracks crosses one of the two Intonachino/Intonaco layer areas (orange damage stage) of the top of the monitored area, (Figure 3). Interaction between orange and yellow factors, B) interaction between orange and white factors 


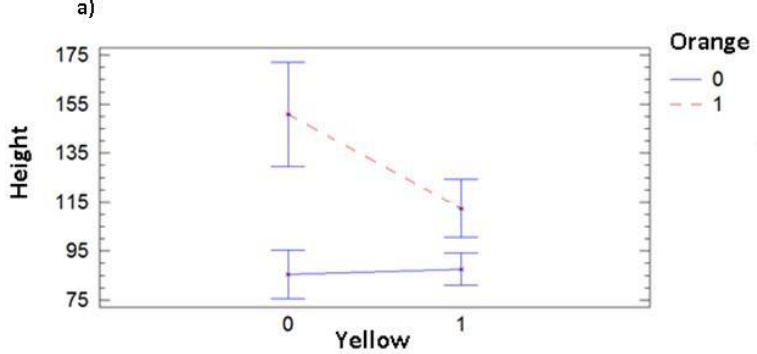

b)

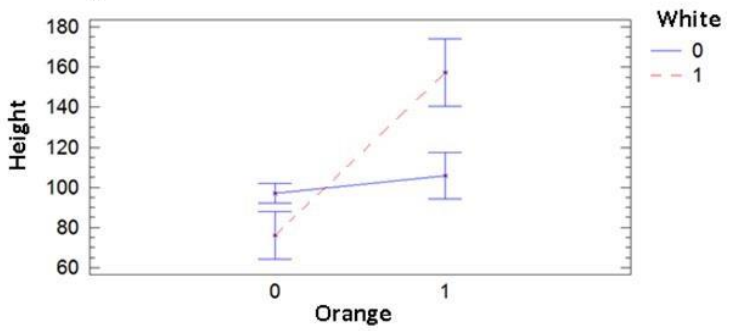

2 On the other hand, considering damage stage factors as categorical variables of 7 levels, the most notable 3 results are given for red damage stage (F-coeficient=7.33, P-value $<0,0001)$ and white damage stage $(\mathrm{F}$ coeficient=18.21, P-value $<0,0001)$.

For red damage the information given is not relevant, since significant differences in height are given for $X_{\mathrm{ij}}$ with a percentage of involvement of this level of damage stage from the 76-99\% (Figure 7. a), but this category has a frequency equal to 1 in this wall, and the average height of $\mathrm{X}_{\mathrm{ij}}$ does not represent the real presence of red damage stage on both walls.

In the case of white damage stage (Figure 7.b) significant differences exist for the category of $100 \%$, which is always in the lowest areas on both walls (average height $X_{\mathrm{ij}}=21.87 \mathrm{~cm}$, standard error $=28.54$ $\mathrm{cm}$ ) because these are cemented by previous interventions and without frescoes remains. Also, it seems remarkable (but not significant at $95 \%$ since the LSD intervals slightly overlap) the difference for the category $76-99 \%$, given at an average height of $59.51 \mathrm{~cm}$ (standard error= $27.89 \mathrm{~cm}$ ). The other categories take place at an average height of $[60.38,160] \mathrm{cm}$. This relation between white damage stage and height seems to have its origin in the higher levels of relative humidity in low areas of the wall by soil moisture contribution (Merello et al. 2012, 2013).

Fig. 7 Main effects for ANOVA with dependent variable height, for both walls, LSD intervals of 95\% and damage stage as categorical factors of 7 levels. A) Red damage stage, B) white damage stage

a)

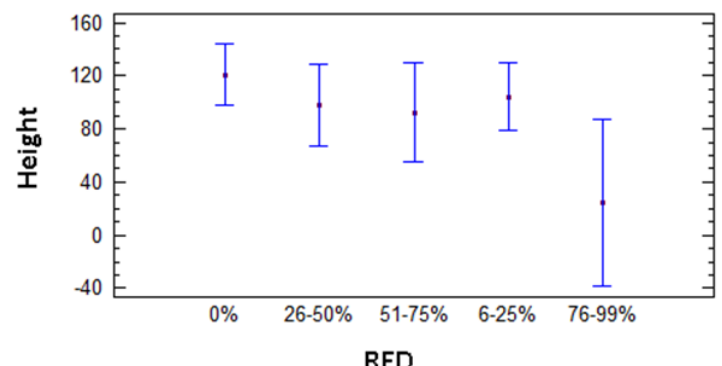

b)

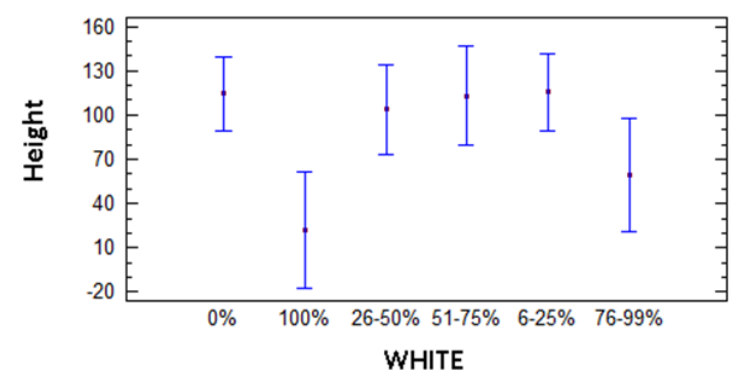

\subsubsection{Column as dependent variable in ANOVA}

Let us be column $j$ of $\mathrm{X}_{\mathrm{ij}}$ the dependent variable in the ANOVA analysis. As for variable height, for column variable all possible combinations have been made.

For the case where stage damage factors are considered as dichotomous variables, the interaction between Green and Wall factors (F-coeficient=17.59, P-value $<0.0001$ ) and between wall and yellow (Fcoeficient $=8.34$, P-value $<0.005$ ) is highlighted. The first interaction indicates that the effect of the presence of green damage stage in $\mathrm{X}_{\mathrm{ij}}$ depends on the studied wall. The presence of green occurs in average in column 6.58 (Standard error $=0.47$, Figure 8.a) in Wall 3, while in wall 4 this damage stage takes place in average at the left end of the wall (mean=1, Standard error=1.43). These dissimilarities may be due to differences in the orientation and the effect of the windows and the door that leads to a difference in temperature and humidity of both walls. 
In the case of yellow damage stage, the presence of this stage damage occurs in average at column 6.89 (standard error $=0.35$, right half of the wall) in wall 3 (Figure 8.b), while in wall 4 it is placed in average

3 at column 2.8 (Standard error $=1.42$, left half of the wall).

4 Fig. 8 ANOVA interactions for analysis with column as dependent variable, Wall factor and damage 5 stage factors as dichotomous variables, with LSD intervals 95\%. A) Interaction between green and wall.

6 B) Interaction between wall and yellow

a)

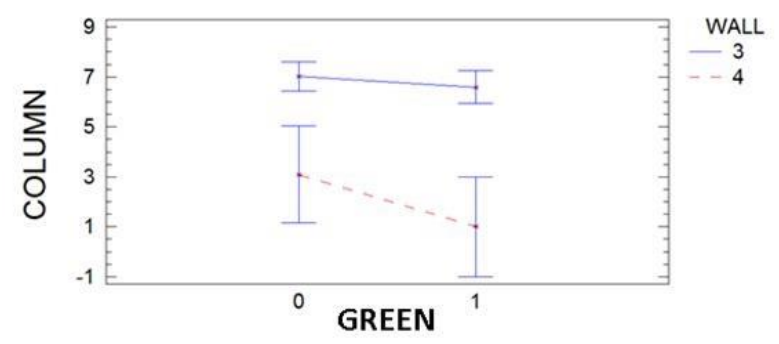

b)

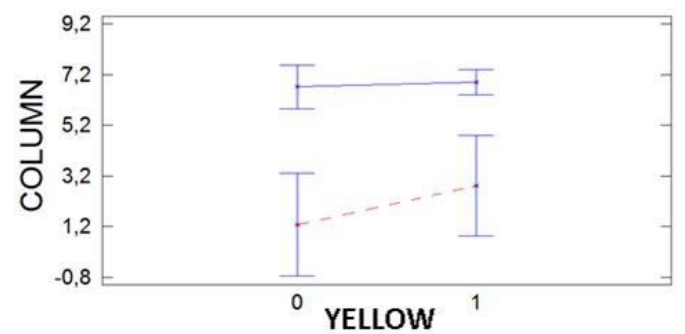

7

On the other hand, considering damage stage factors as categorical variables of 7 levels, the most noticeable results are given for red factor (F-coeficient $=8.52$, P-value $<0,0001$ ) and burgundy stage damage $($ F-coeficient=16.26, P-value $<0,0001)$.

In the case of red damage stage (Figure 9.a), significant differences on variable column are find for $X_{\mathrm{ij}}$ with a 76-99\% of involvement of this level of damage stage, therefore it takes place at the central area of both walls $($ mean $=6.05$, standard error $=3.24$, frequency $=1)$, since the presence of this category of this factor decreases the average column in $\mathrm{X}_{\mathrm{ij}}$. However, no robust conclusions can be written as the frequency of this interval is equal to 1 .

In the case of burgundy damage stage (Figure 9.b) the differences are significant for category of $0 \%$, since the presence of this category decreases the average column in $\mathrm{X}_{\mathrm{ij}}$, showing that areas with no material are normally placed at the right of the wall. Note that the average column for an affectation of $51-75 \%$ (similar results for 76-99\%) is 11.16 (standard error $=1.84$ ). As 11.16 is bigger than 9 , which are the columns of wall 4 , this points to wall 3 and the large brick missing at the right side.

Fig. 9 ANOVA main effects for analysis with column as dependent variable, data from both walls, LSD intervals 95\%, and categorical damage stage factors of 7 levels. A) red damage stage, B) burgundy damage stage

a)

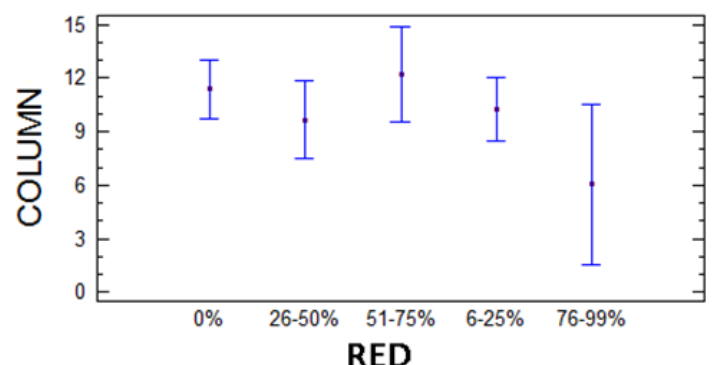

b)

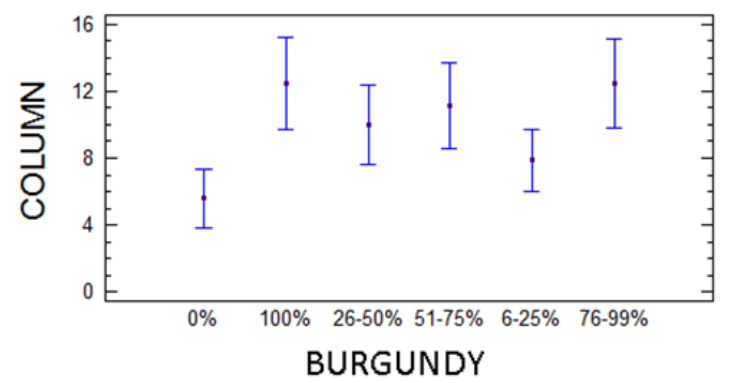

The above results show how is possible to draw significant conclusions about the damage eaused by salt efflorescences in frescoes as well as its relationship with the morphology of the wall or other more causal variables related to these.

On the one hand, and based on image recognition technology, nowadays some authors are working on the 
colours deterioration on them (Guarneri et al. 2014). Our proposal is similar, since damage stage is evaluated cell by cell, but based on visual inspection. Our methodology is less automated but of a simpler and direct application for restorers and curators. Furthermore, our methodology implies the quantification of these damage stages building a data matrix which allows crossing this data with other qualitative (orientation, salts damage, etc.) or quantitative variables (RH, temperature, light, etc.) achieving further explanation of the causes of degradation.

In connection with this, other authors (O'Brien 1990) analyse which variables have an effect on the salt erosion using for this the design of experiments. Our methodology favours this kind of studies in places where it is not possible to make an experiment and yet it is very important to know in situ the different amount of salt erosion and its possible causes, this is the case of frescoes in archaeological sites.

\section{CONCLUSIONS}

The methodology proposed in this paper has proved was useful in quantifying and empirically demonstrating significant differences between different damage stages produced by salts and their relationship with the morphological characteristics of the analysed-wall. In contrast to normal damage mapping procedures by visual inspection commonly used in cultural heritage, our approach is able to quantify more accurately because the assessment is performed on a grid with cells of $2.5 \mathrm{~cm} \times 2.5 \mathrm{~cm}$ and assigning a stage of damage to each cell.

After defining six stages of damage, a colorimetric map of damage has been performed for each wall. These maps allow a fast evaluation and guidance for restorers and curators as well as for an accurate budgeting of restoration work.

The analysis of variance (ANOVA) conducted on data matrices obtained from the quantification of the damage stage affectation per walls, reflected significant differences for the height and horizontal axis (column). Are noticeable those differences in height, especially for white damage stage, which are mainly caused by the contribution of soil moisture. On the other hand, differences in column may be attributed to differences in wall orientation and the presence of windows.

However, the causes of these differences have not been analysed. This justifies the interest and future use of the proposed technique to cross the obtained data with other variables different to the morphological but related to these, as for example microclimate variables (temperature and humidity), materials (original material degradation and restoration materials) or salts analytics.

As far as the authors know, this is first time that qualitative-quantitative data obtained from damage mapping in frescoes are analysed by ANOVA and reported.

\section{Conflict of interest}

The authors declare that they have no conflict of interest.

\section{REFERENCES}

Arnold A, Zehnder K (1996) Monitoring wall paintings affected by soluble salts. In: Cather S (ed) The Conservation of Wall Paintings, 2nd edn. Courtauld Institute of Art and the Getty Conservation Institute, London, pp 103-136.

Goudie AS, Viles HA (1997) Salt weathering hazards, Wiley, London.

Guarneri M, Danielis A, Francucci M, De Collibus MF, Fornetti G, Mencattini A (2014) 3D remote colorimetry and watershed segmentation techniques for fresco and artwork decay monitoring and

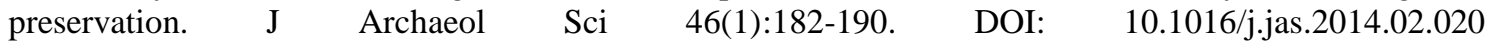

Hamamcioglu-Turan M, Akbaylar I (2011) Documentation of historic structures for the assessment of heritage characteristics. J Archit Plan Res 
Merello P, García-Diego FJ, Zarzo M (2012) Microclimate monitoring of Ariadne's house (Pompeii, Italy) for preventive conservation of fresco paintings. Chem Cent J 6:145. DOI: 10.1186/1752-153X-6145

Merello P, García-Diego FJ, Zarzo M (2013) Evaluation of corrective measures implemented for the preventive conservation of fresco paintings in Ariadne's house (Pompeii, Italy). Chem Cent J 7(1):87. DOI:

$10.1186 / 1752-153 X-7-87$

Myra J, Giesena A, Ungb P, Warkec A, Christgenb B, Mazela AD, Grahamb DW (2014) Condition assessment and preservation of open-air rock art panels during environmental change. J Cult Herit 15:4956.

DOI:

10.1016/j.culher.2013.01.013

Nevin A, Melia JL, Osticioli I, Gautier G, Colombini MP (2008) The identification of copper oxalates in a 16th century Cypriot exterior wall painting using micro FTIR, micro Raman spectroscopy and Gas Chromatography-Mass Spectrometry J Cult Herit 9:154-161. DOI: 10.1016/j.culher.2007.10.002.

O'Brien P (1990) An experimental study of the effects of salt erosion on pottery. J Archaeol Sci 17(4):393-401. DOI: 10.1016/0305-4403(90)90004-O.

Pérez MC, Garcia-Diego FJ, Merello P, D’Antoni P, Fernández Navajas A, Ribera i Lacomba A, Ferrazza L, Pérez-Miralles J, Baró JL, Merce P, D’Antoni H, Curiel J (2013) Ariadne's house (Pompeii, Italy) wall paintings: A multidisciplinary study of its present state focused on a future restoration and preventive conservation. Mater Construcc 63(311):449-467. DOI: 10.3989/mc.2012.00812.

Pesando F (1997) Domus: edilizia privata e società pompeiana fra III e I secolo a.C., "L'Erma" di Bretschneider, Rome.

Pesando F (2007) La Casa de Ariadna de Pompeya: redescubrimiento de una domus. In: Ribera A, Olcina M, Ballester C (ed) Pompeya bajo Pompeya, Las excavaciones en la Casa de Ariadna. Museo Arqueológico Provincial de Alicante (MARQ), Valencia, pp 21-23.

Rodriguez-Navarro C, Doehne E (1999) Salt weathering: influence of evaporation rate, supersaturation and crystallization pattern. Earth Surf Process Landf 24:191-209. DOI: 10.1002/(SICI)10969837(199903)24:3<191::AID-ESP942>3.0.CO;2-G

Ruiz-agudo E, Lubelli B, Sawdy A, Van Hees R, Price C, Rodriguez-Navarro C (2011) An integrated methodology for salt damage assessment and remediation: The case of San Jerónimo Monastery (Granada, Spain). Environ Earth Sci 63(7):1475-1486. DOI: 10.1007/s12665-010-0661-9

Statgraphics Software 5.1. Available online. http://www.statgraphics.net/. Accessed 18 March 2015.

Warke PA, Curran JM, Turkington AV, Smith BJ (2003) Condition Assessment for Building Stone Conservation: A Staging System Approach. Build Environ 38:1113-1123. DOI: 10.1016/S03601323(03)00085-4.

Weritz F, Kruschwitz S, Maierhofer C, Wendrich A (2009) Assessment of moisture and salt contents in brick masonry with microwave transmission, spectral-induced polarization, and laser-induced breakdown spectroscopy. Int J Archit Herit 3(2):126-144. DOI: 10.1080/15583050802278992

Winkler EM (1994) Stone in architecture, Springer, Berlin Heidelberg.

Wüst R, Schlüchter C (2000) The origin of soluble salts in rocks of the Thebes mountains, Egypt: The damage potential to ancient Egyptian wall art. J Archaeol Sci 27(12):1161-1172. DOI: 10.1006/jasc.1999.0550 
Click here to download Figure: F1.jpg

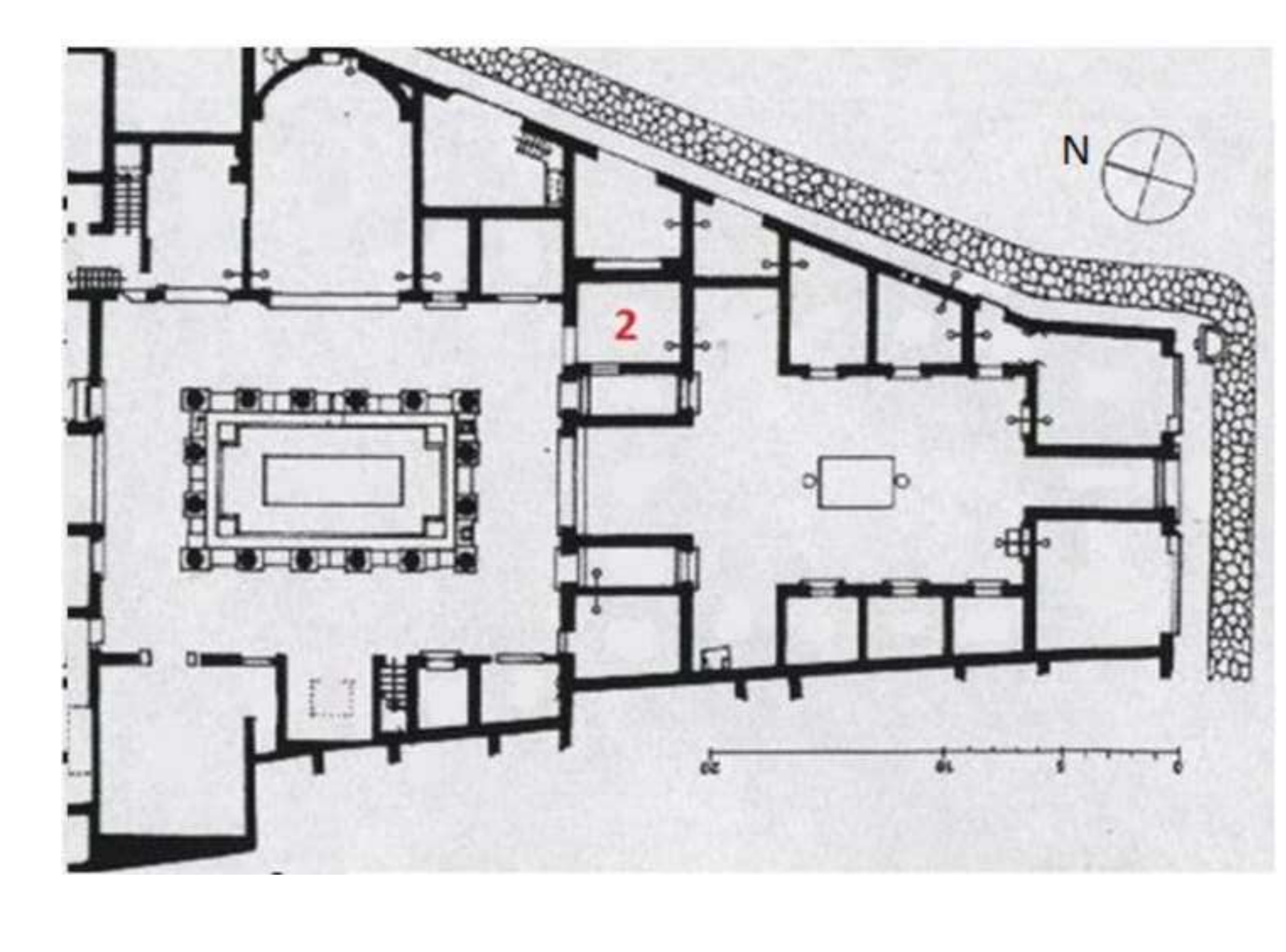

$$
\text { . }
$$




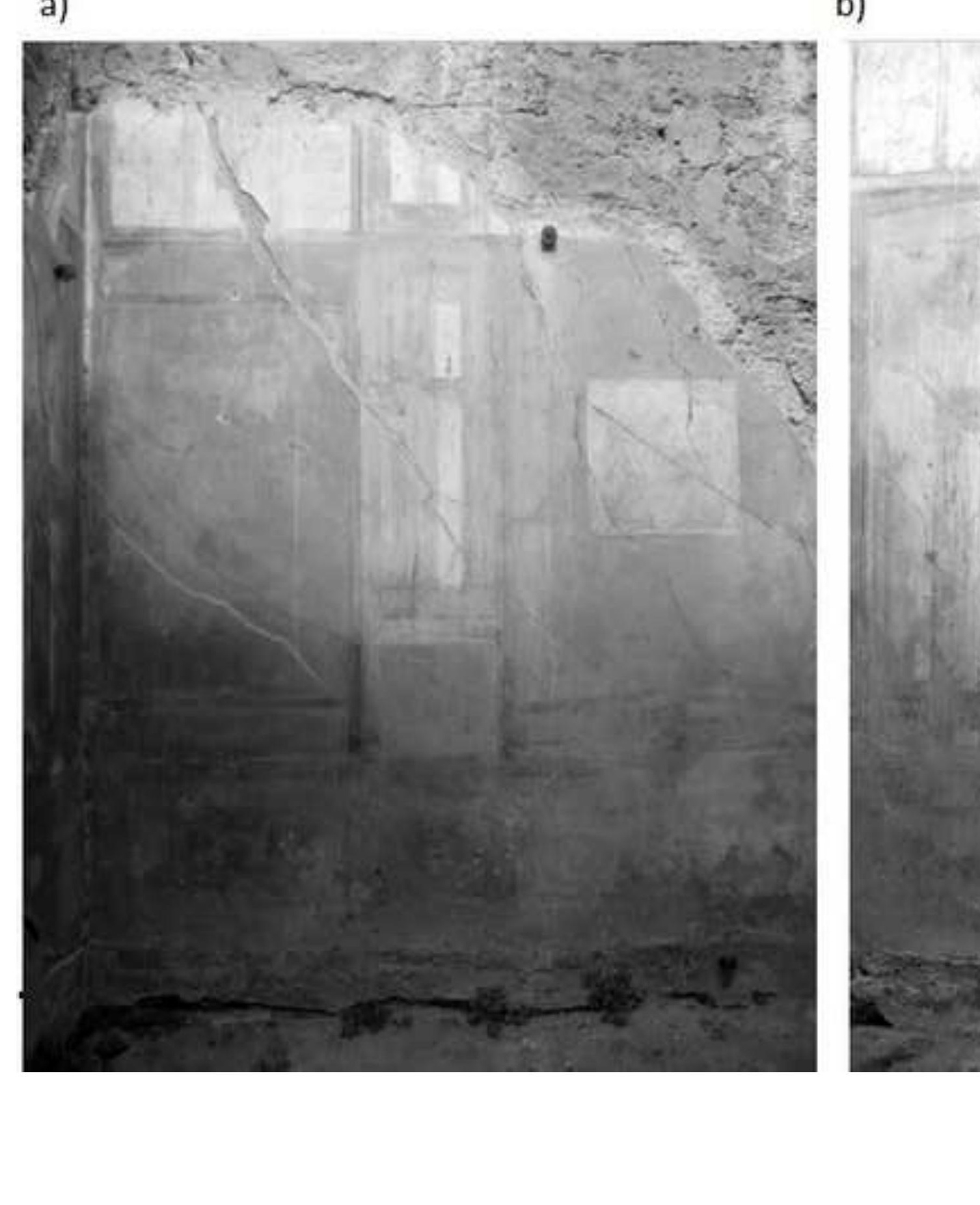

b)

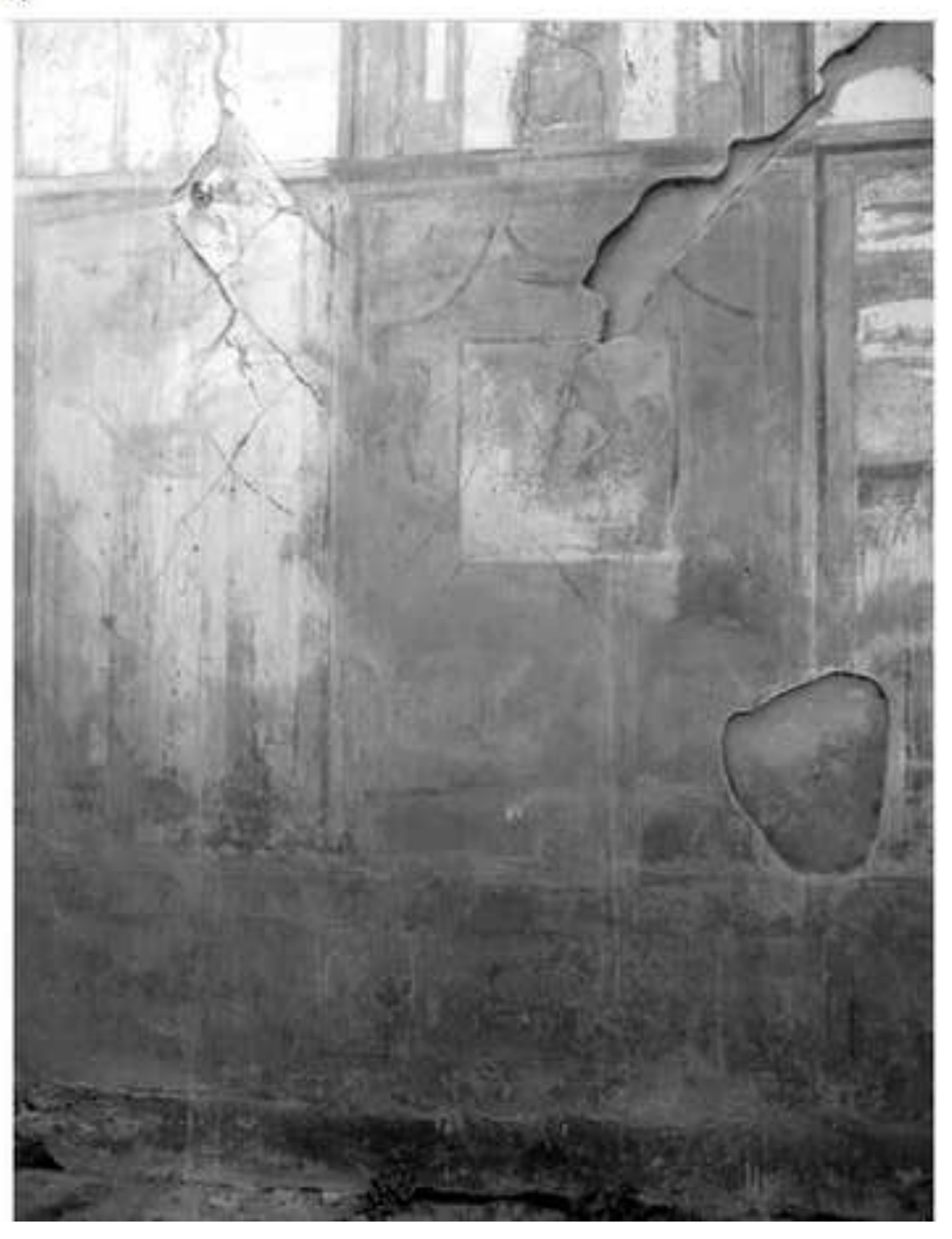

)
Click here to download Figure: F2.jpg

a)

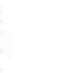

. .}

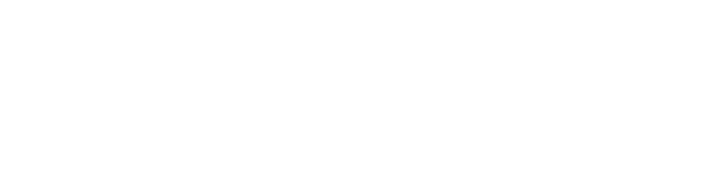

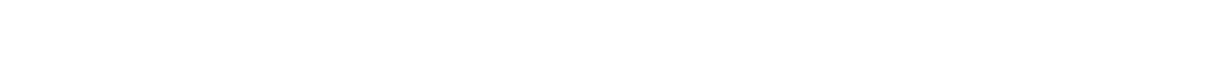

(1)

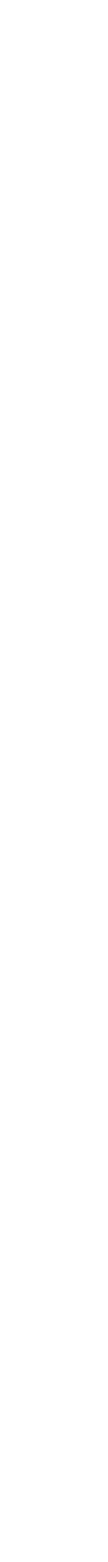


Click here to download Figure: F3.jpg

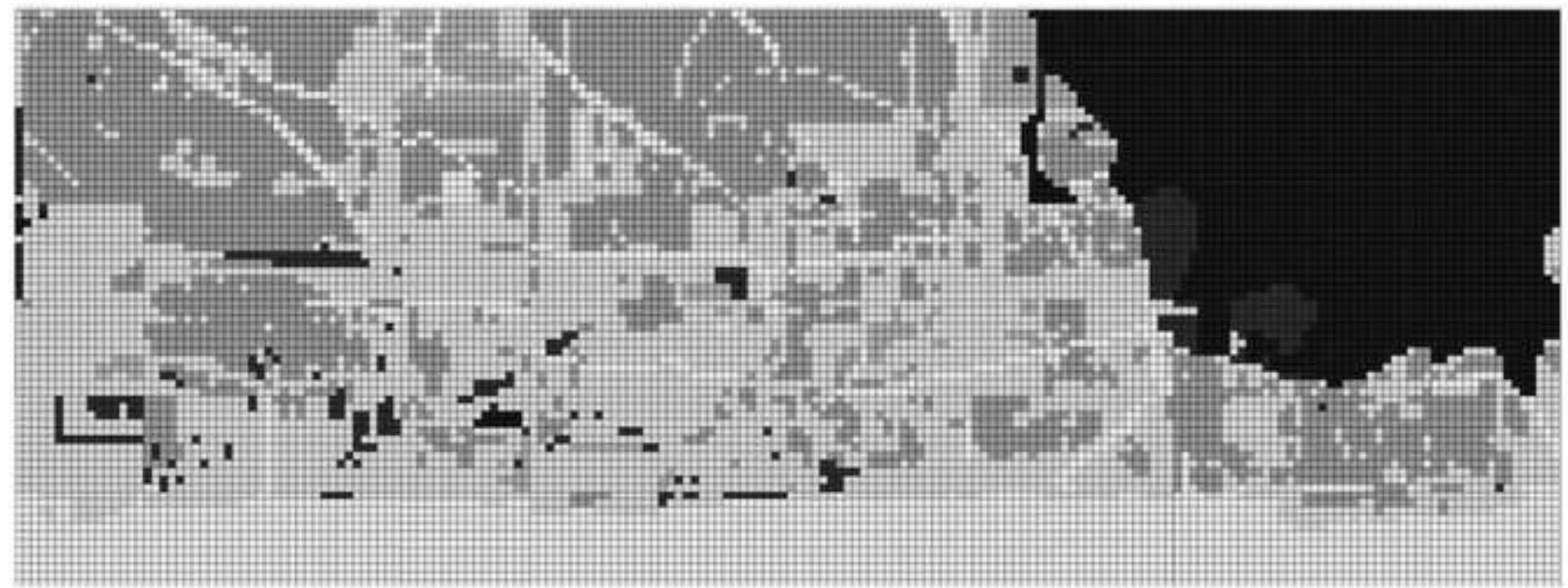

\begin{tabular}{|l|}
\hline 1 \\
\hline 2 \\
\hline 3 \\
\hline 4 \\
\hline 5 \\
\hline 0 \\
\hline
\end{tabular}

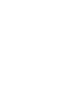


Click here to download Figure: F4.jpg
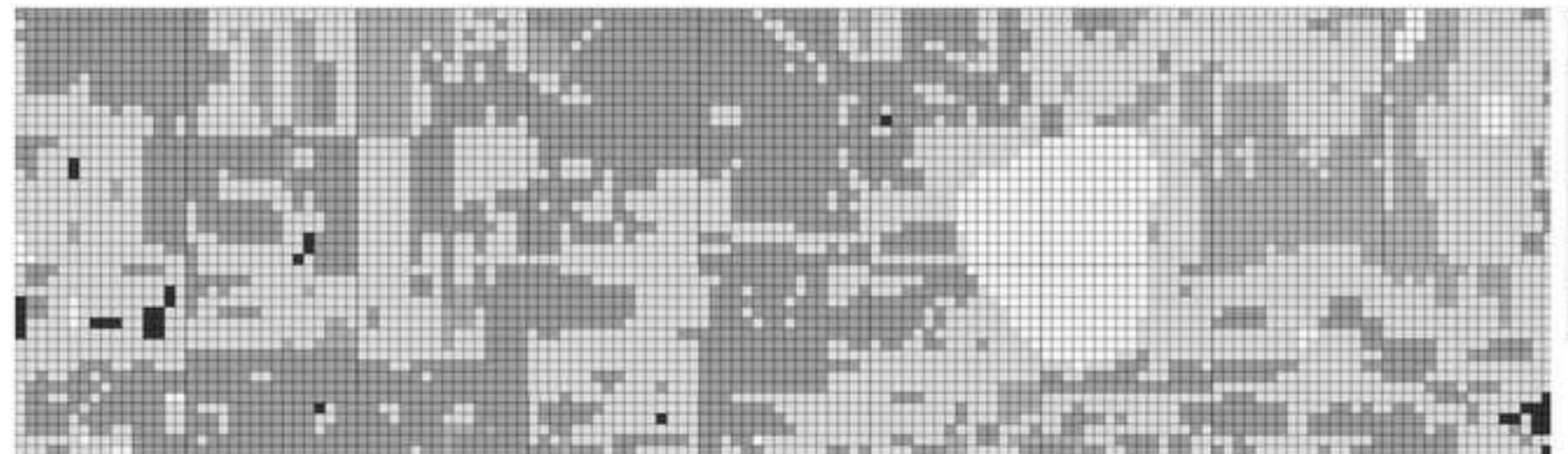

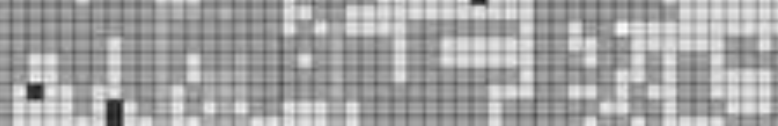

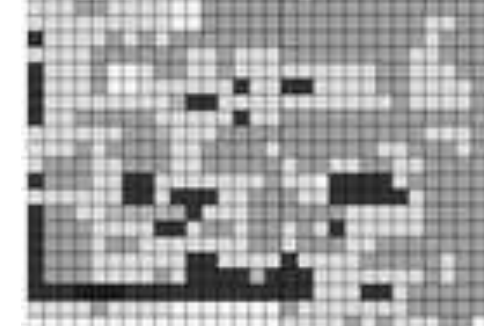

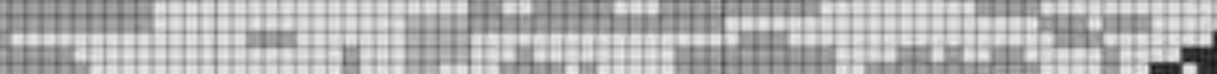

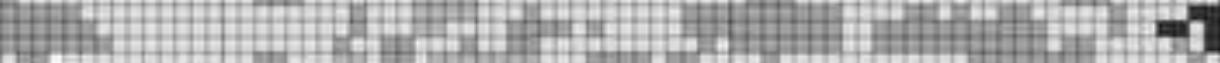

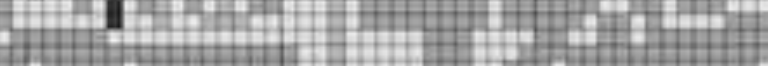
If:

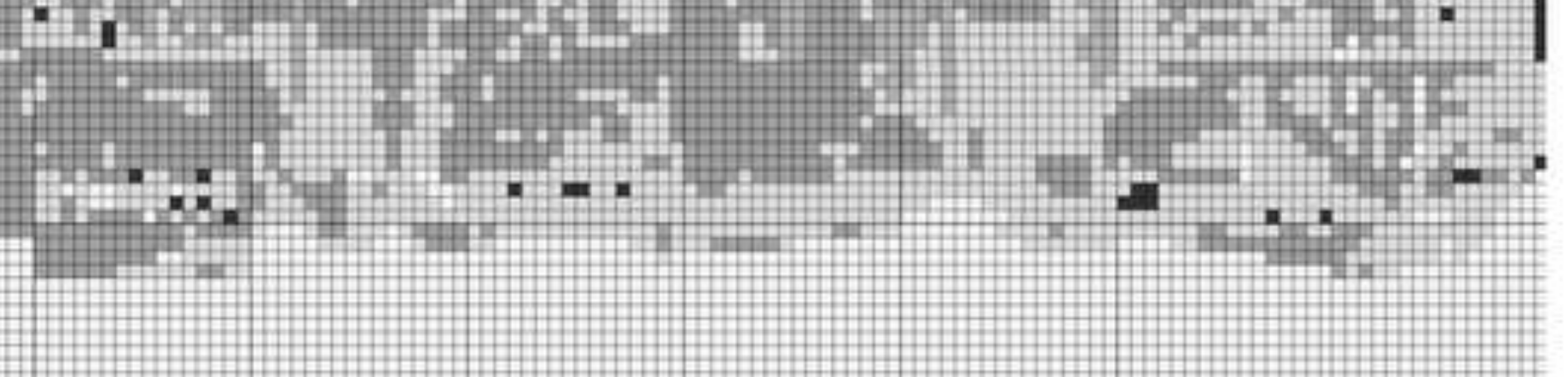

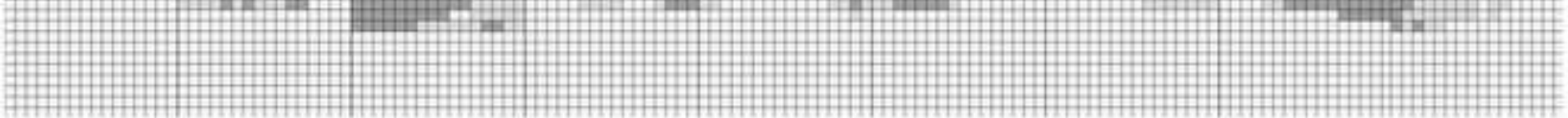


Figure 5
Click here to download Figure: F5.jpg

a)

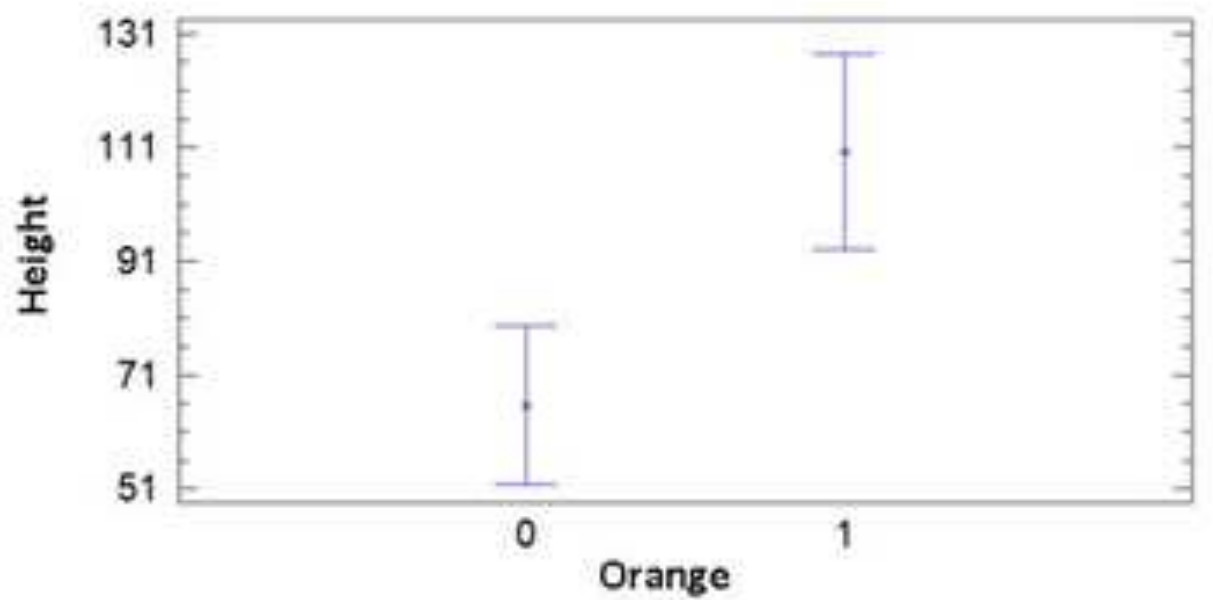

b)

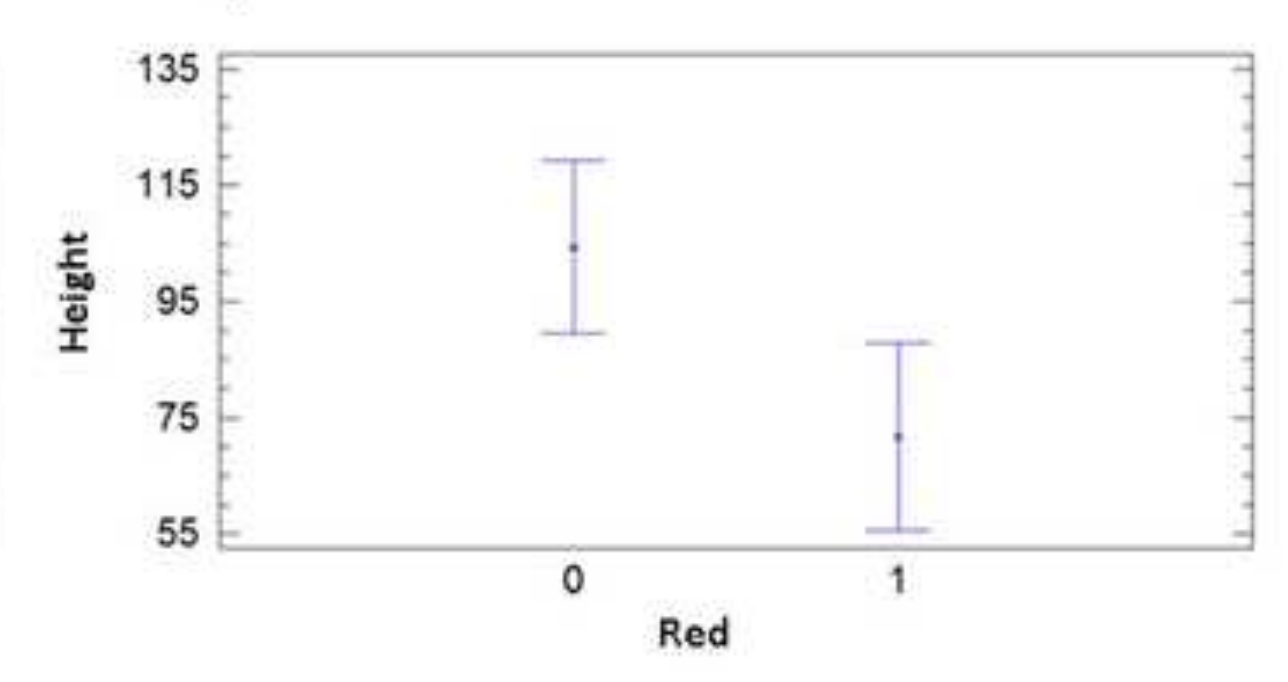

) 
Click here to download Figure: F6.jpg

a)

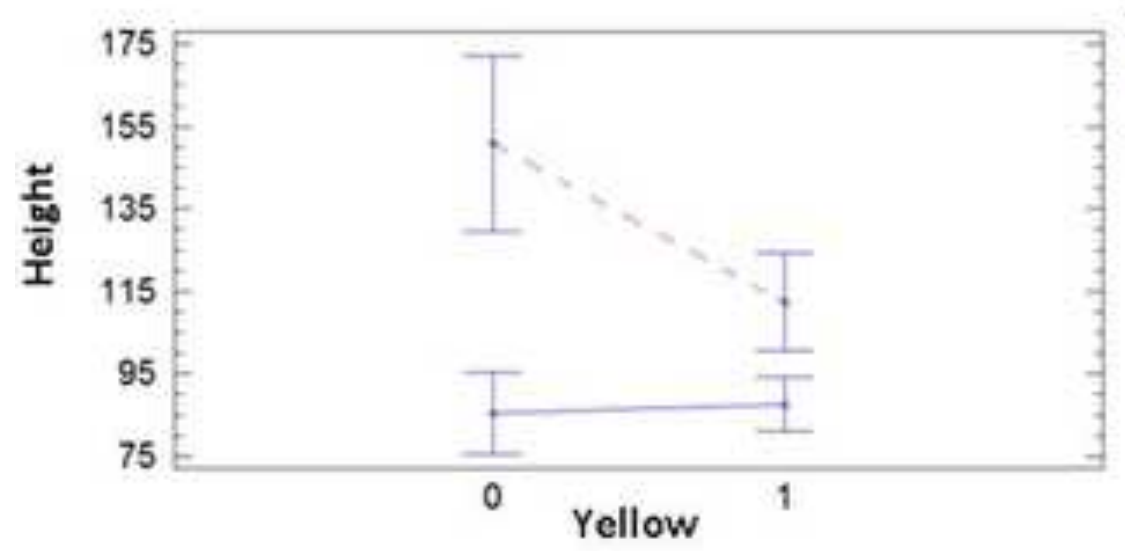

b)

Orange

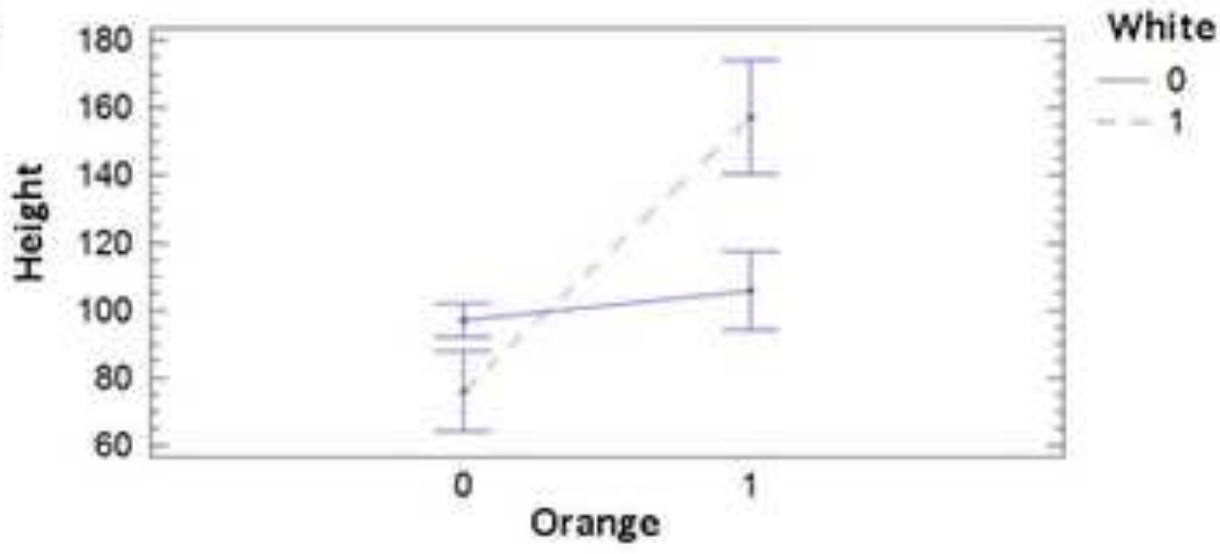

White -0
-1 
a)

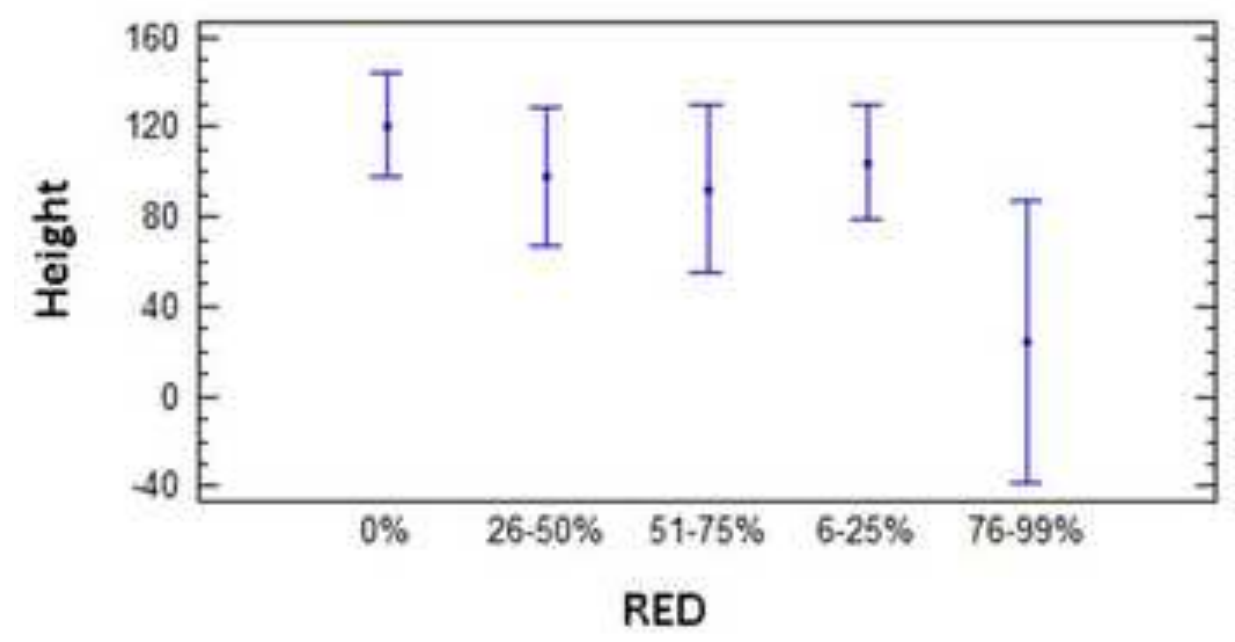

b)

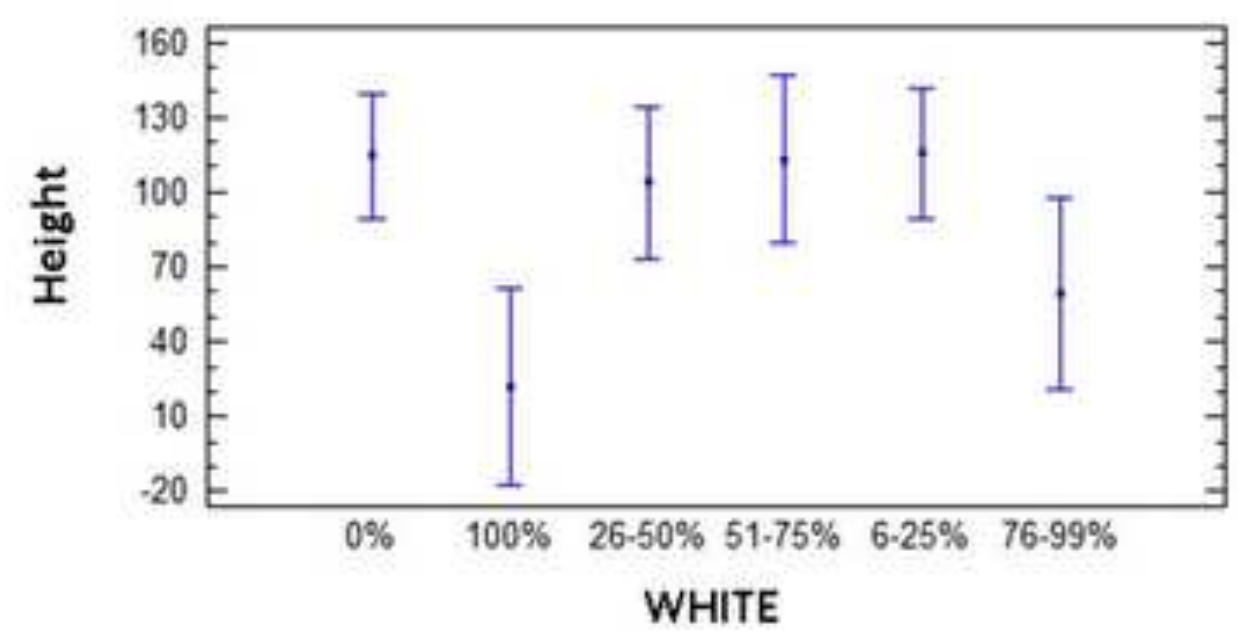


a)

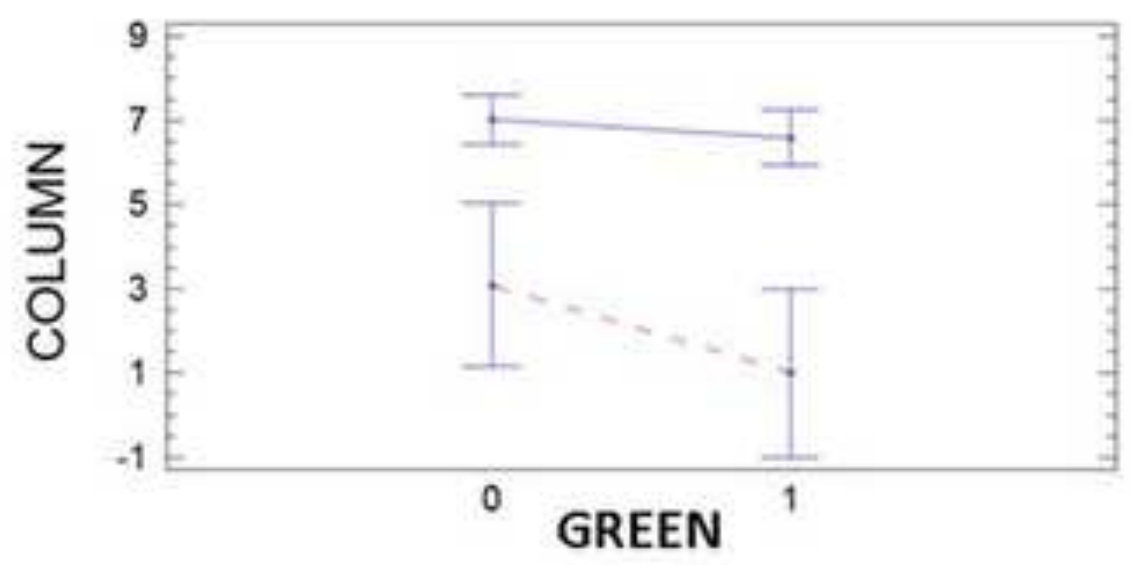

b)

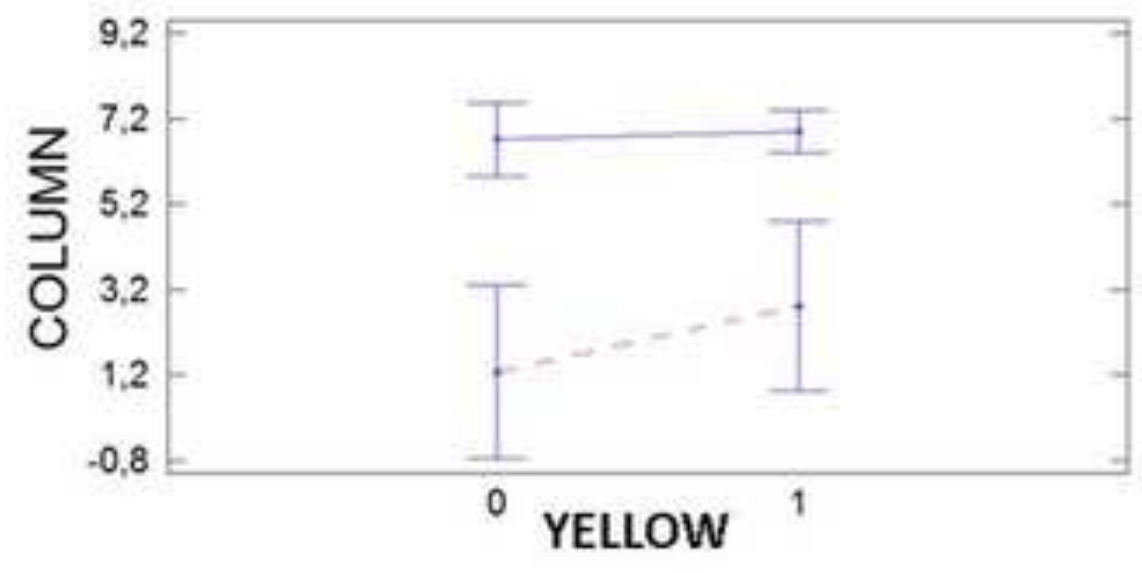

WALL

-3
$-\quad 4$
-4

YELLOW 
a)

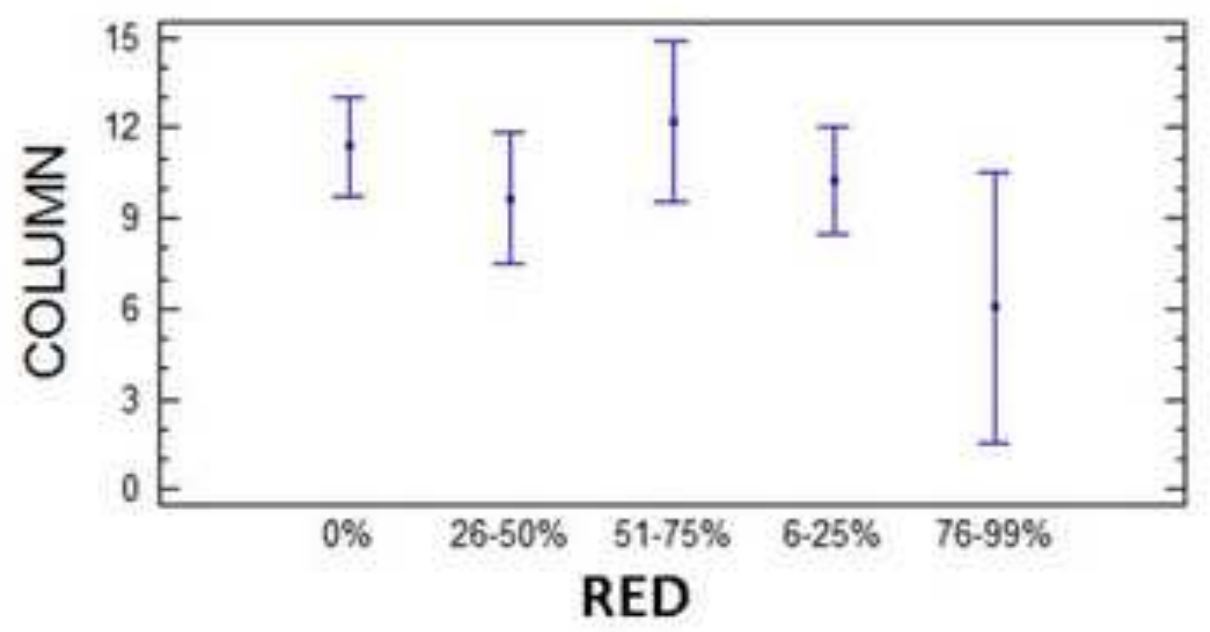

b)

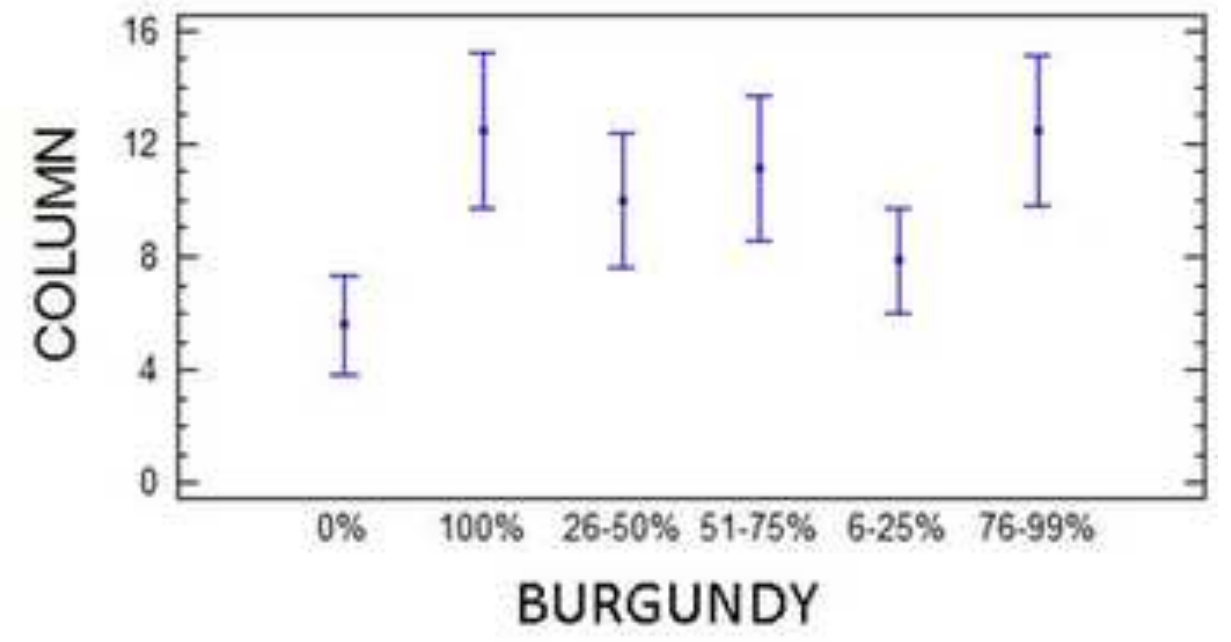


Table 1. Damage stage definition.

\begin{tabular}{|l|l|l|}
\hline Colour & $\begin{array}{l}\text { Numerical scale } \\
\text { equivalence }\end{array}$ & Damage definition \\
\hline Green & 1 & Paint layer. Best conservation state of the studied frescoes. \\
\hline Yellow & 2 & $\begin{array}{l}\text { Paint layer decay or salts efflorescences (superficial } \\
\text { cleaning by mechanical techniques needed) }\end{array}$ \\
\hline Orange & 3 & Intonachino/Intonaco layer \\
\hline Red & 4 & Intonaco/Arriccio layer \\
\hline Burgundy & 5 & Brick wall \\
\hline White & 0 & $\begin{array}{l}\text { Area with previous restoration. The restoration is visually } \\
\text { noticeable. }\end{array}$ \\
\hline
\end{tabular}

Table 2. Descriptive statistical values for damage stage in wall 3 and 4. Descriptive statistics: total of cells of the colour per wall, percentage of cells of the colour per wall, average of cells of the colour in each row per wall, standard deviation of the cells of the colour per row and wall.

\begin{tabular}{|l|l|l|l|l|l|l|}
\hline & Green & Yellow & Orange & Red & Burgundy & White \\
\hline Wall 3 & & & & & & \\
\hline Total cells & 3496 & 4773 & 347 & 396 & 2317 & 2491 \\
\hline Percentage over the total (\%) & 25.3 & 34.5 & 2.5 & 2.9 & 16.8 & 18.0 \\
\hline Average & 4.1 & 5.5 & 0.4 & 0.5 & 2.7 & 2.9 \\
\hline Stand. Dev & 5.0 & 5.4 & 1.7 & 1.5 & 5.7 & 5.5 \\
\hline Wall 4 & & & & & & \\
\hline Total & 3461 & 4190 & 710 & 126 & 3 & 1877 \\
\hline Percentage over the total (\%) & 33.4 & 40.4 & 6.9 & 1.2 & 0.03 & 18.1 \\
\hline Average & 5.3 & 6.5 & 1.1 & 0.2 & 0.00 & 2.9 \\
\hline Stand. Dev & 5.2 & 4.9 & 2.5 & 0.9 & 0.1 & 5.6 \\
\hline
\end{tabular}


Table 3. Significant factors (p-value<0.05), ANOVA height as dependent variable and damage stage (dummy) and wall as independent factors.

\begin{tabular}{|c|c|c|c|c|c|}
\hline Variable & $\begin{array}{l}\text { Sum of } \\
\text { Squares }\end{array}$ & $\begin{array}{l}\text { Freedom } \\
\text { degrees }\end{array}$ & $\begin{array}{l}\text { Mean } \\
\text { Square }\end{array}$ & F-Coeficient & P-Value \\
\hline \multicolumn{6}{|l|}{ MAIN EFFECTS } \\
\hline Orange & 43925.6 & 1 & 43925.6 & 32.00 & 0.0000 \\
\hline Red & 29187.6 & 1 & 29187.6 & 21.26 & 0.0000 \\
\hline \multicolumn{6}{|l|}{ INTERACTIONS } \\
\hline Wall * Green & 53673.0 & 1 & 53673.0 & 39.10 & 0.0000 \\
\hline Wall * Yellow & 10719.0 & 1 & 10719.0 & 7.81 & 0.0052 \\
\hline Wall * Orange & 14688.3 & 1 & 14688.3 & 10.70 & 0.0011 \\
\hline Wall * Red & 10277.7 & 1 & 10277.7 & 7.49 & 0.0062 \\
\hline Wall * White & 13988.3 & 1 & 13988.3 & 10.19 & 0.0014 \\
\hline Green * Yellow & 13120.1 & 1 & 13120.1 & 9.56 & 0.0020 \\
\hline Green * Orange & 9636.77 & 1 & 9636.77 & 7.02 & 0.0081 \\
\hline Green * Burgundy & 32010.0 & 1 & 32010.0 & 23.32 & 0.0000 \\
\hline Yellow * Orange & 7163.06 & 1 & 7163.06 & 5.22 & 0.0224 \\
\hline Yellow * Burgundy & 5880.16 & 1 & 5880.16 & 4.28 & 0.0385 \\
\hline Yellow * White & 26886.9 & 1 & 26886.9 & 19.58 & 0.0000 \\
\hline Orange * White & 54135.6 & 1 & 54135.6 & 39.43 & 0.0000 \\
\hline Burgundy * White & 6716.76 & 1 & 6716.76 & 4.89 & 0.0270 \\
\hline RESIDUALS & $2.03592 \mathrm{E} 6$ & 1483 & 1372.84 & & \\
\hline $\begin{array}{l}\text { TOTAL } \\
\text { (CORRECTED) }\end{array}$ & $4.08041 \mathrm{E} 6$ & 1511 & & & \\
\hline
\end{tabular}

